\title{
A systematic summary of survival and death signalling during the life of hair follicle stem cells
}

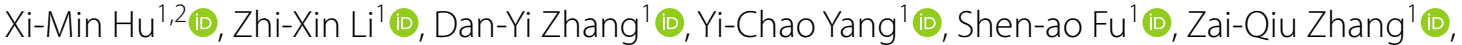 \\ Rong-Hua Yang ${ }^{3^{*}}$ (D) and Kun Xiong ${ }^{1,4^{*}}$ (])
}

\begin{abstract}
Hair follicle stem cells (HFSCs) are among the most widely available resources and most frequently approved model systems used for studying adult stem cells. HFSCs are particularly useful because of their self-renewal and differentiation properties. Additionally, the cyclic growth of hair follicles is driven by HFSCs. There are high expectations for the use of HFSCs as favourable systems for studying the molecular mechanisms that contribute to HFSC identification and can be applied to hair loss therapy, such as the activation or regeneration of hair follicles, and to the generation of hair using a tissue-engineering strategy. A variety of molecules are involved in the networks that critically regulate the fate of HFSCs, such as factors in hair follicle growth and development (in the Wnt pathway, Sonic hedgehog pathway, Notch pathway, and BMP pathway), and that suppress apoptotic cues (the apoptosis pathway). Here, we review the life cycle, biomarkers and functions of HFSCs, concluding with a summary of the signalling pathways involved in HFSC fate for promoting better understanding of the pathophysiological changes in the HFSC niche. Importantly, we highlight the potential mechanisms underlying the therapeutic targets involved in pathways associated with the treatment of hair loss and other disorders of skin and hair, including alopecia, skin cancer, skin inflammation, and skin wound healing.
\end{abstract}

Keywords: Hair follicle stem cells (HFSCs), Signalling, Wnt, Shh, Notch, BMP, Apoptosis

\section{Introduction}

Hair contributes to a healthy life of human beings through their sensory effects, thermoregulation, physical protection, and social interaction impacts. In this regard, disorders of skin and hair, such as alopecia, anagen effluvium, telogen effluvium, hirsutism, hypertrichosis, and miniaturization, negative affect health [1]. Alopecia is a serious problem affecting $60-70 \%$ of the adult population

\footnotetext{
*Correspondence: 21720091@qq.com; xiongkun2001@163.com

${ }^{1}$ Department of Anatomy and Neurobiology, School of Basic Medical

Sciences, Central South University, Morphological Sciences Building, 172 Tongzi Po Road, Changsha 410013, China

${ }^{3}$ Department of Burn Surgery, The First People's Hospital of Foshan, \#81, Lingnan North Road, Foshan 528000, China

Full list of author information is available at the end of the article
}

worldwide, up to $70 \%$ of men and $40 \%$ of women, costing more than 3.5 billion every year in the U.S.A. [2, 3]. The regeneration of hair shafts produced by hair follicles (HFs) relies on the activation of a major reservoir of hair follicle stem cells (HFSCs), which is therefore utilized in stem cell-based therapy for treating alopecia.

The HF, a complex mini-organ of the skin, provides the stem cell (SC) microenvironment "niche", functioning as a crucial regulator of cell fate by controlling the consecutive cycles of hair growth rest (the telogen phase), active hair growth (the anagen phase), and apoptotic-mediated hair growth regression (the catagen phase). This process depends on an elaborate network formed through multiple pathways, such as the Wnt/ $\beta$-catenin pathway, Sonic hedgehog (Shh) pathway, Notch pathway, BMP 
(bone morphogenetic proteins) pathway and apoptotic pathway. Among these pathways, the $\mathrm{Wnt} / \beta$-catenin signalling pathway plays a diverse role in initiating HFSCs for hair growth during hair regeneration [4]. Upregulation of Wnt10b or activation of Akt and Wnt/ß-catenin can induce HFSCs to enter anagen from the telogen phase, resulting in accelerated hair regeneration $[5,6]$. In addition, the proliferation of quiescent SCs can be induced by Shh pathway activation, and hair morphogenesis is closely related to Shh signalling [7]. Moreover, HFSC progeny secrete Shh, leading to the initiation of HF regeneration in adults [8]. The Notch pathway is a major mechanistic pathway in the fate determination of HFSCs, and the Maria group and Niwa group showed that Notch signalling promoted HFSC activation in a regulatory $\mathrm{T}$ cell (Treg)-mediated manner $[9,10]$. Furthermore, BMP signalling is regarded as a suppressant of HFSC activity, whereas TGF- $\beta 2$ signalling can antagonize BMP signalling to promote HF regeneration [11]. Apoptotic signalling is also vital for the pathological (e.g., following radiation-induced damage) and physiological (e.g., catagen phase) processes in which molecules known as caspase or Bcl-2 are activated [12]. Through a unique molecular mechanism, each of these proteins exerts special functions, while complex connections are established between them. For example, BMP signalling is not activated at the same time as the $\mathrm{Wnt} / \beta$-catenin signalling pathway, but the Wnt pathway can be inhibited by BMP expression, and sustained Shh expression relies on BMP inhibition [13, 14].

HFSCs have been shown to differentiate into nerve cells, glial cells, keratinocytes, smooth muscle cells, cardiac muscle cells, and melanocytes, which suggests tremendous potential for HFSCs as targets in the treatment of various diseases. Genetic profiling of HFSCs has revealed several known and previously unknown molecules and signalling pathways, including those involved not only in survival but also in death mechanisms, which are important for maintaining the SC phenotype. Ultimately, these findings indicate a number of potential targets for the treatment of hair loss and other skin and hair disorders.

\section{A brief introduction to HFSCs}

\section{HFSC status in the hair cycle and niche microenvironment}

An HF is known as a complex mini-organ embedded in the skin that is formed by the papilla, matrix, root sheath and bulge. And the tissue homeostasis in HFs and their damage repair rely on a variety of stem cells within the HFs, including HFSCs mostly located in the hair follicle bulge, keratinocyte progenitor cells from the hair follicle bulge area, melanocyte progenitor cells, nestin-expressing stem cells, skin-derived precursors (SKPs) located in the DP, and also stem cells in eccrine gland and sebaceous gland [15-20]. HFSCs constitute the major portion of SCs in HFs, which are derived from the neuroectoderm and exhibit the potential to differentiate into multiple cell types [21]. Due to the discovery of HFSCs, we have made a deeper insight into the growth, development and regulation of HFs [16, 22, 23]. And the term 'HFSCs' was first coined in 1990s, which is first identified in the bulge epithelium as label-retaining cells (LRCs) [16].

During HF cycling (the telogen, anagen, and catagen phases) and/or injury repair, HFSCs may remain quiescent continuously or acquire a different status, engaging the mechanism(s) to respond to their own niche microenvironment. In the telogen phase, HFSCs are located in the bulge and maintain quiescence because of various inhibiting factors. The dermal papilla (DP) is located immediately below the bulge, and it can secrete factors to regulate the state of HFSCs. Once a critical concentration of SC activators has been reached, a subset of HFSCs is activated, and the anagen phase is initiated [24]. Interestingly, only a small number of HFSCs near the DP undergo asymmetric division and become transient amplifying cells (TACs). The remaining HFSCs remain in the bulge and maintain quiescence. In the anagen phase, TACs differentiate into the matrix and sheath of a hair shaft, forming the lower part of an HF [1]. Then, the bulge and DP gradually move away. During the catagen phase, the lower two-thirds of the HF rapidly regress. The lower HF is reduced to an epithelial strand, bringing the dermal papilla into close proximity of the bulge [25]. The signalling molecules that regulate HFSCs are mainly derived from the DP.

With the regulation of the HFSC life cycle, a complex and vital element may point to the niche as well as to the other microenvironments (including dermal papilla, adipose tissue, lymphatic vessels, nerves and immune cells, etc.) [26]. For example, a vast amount of lipids are stored in mature adipocytes and supply energy for SC proliferation and rapid hair production/elongation [27]. A detailed review of the molecular pathways involved in HFSCs is presented herein.

\section{Specific markers of HFSCs and the HF structure}

To identify and separate HFSCs from other HF cells, knowing their location and the specific markers is necessary [28]. The longitudinal surface of an HF can be divided into three parts from the epidermis to deep layers: the infundibulum (from the surface of the skin to the duct of the sebaceous gland), the isthmus (from the duct of the sebaceous gland to the attachment of the arrector pili muscle, APM) and the hair bulb (below the attached APM). It can also be divided in the horizontal direction; that is, the HF consists of an inner root sheath 
(IRS), which includes Henle's layer, Huxley's layer, the cuticle layer, the companion layer, and the outer root sheath (ORS), which contains keratinocytes, melanocyte stem cells, etc. The prominent bulge between the APM attached to the ORS and the sebaceous gland duct is the reservoir of human HFSCs (hHFSCs) [1, 29, 30]. We provide a figure of the HF structure and the specific markers of HFSCs (Fig. 1).

With further research on hHFSCs in recent years, the accurate identification of hHFSCs has become an important problem to be solved. Due to the complexity of the HF structure and cell composition, it is generally believed that a combination of multiple markers should be used to identify HFSCs in the bulge.

CK15 was one of the first identified hHFSC markers and is expressed in all stages of human bulge cells [3133]. It has been widely used in identifying hHFSCs and is considered to be one of the best markers of hHFSCs [30, $34,35]$. However, CK15 was also found to be continuously expressed in the basal epidermal layer, sweat glands and oral epithelial cells, which raised concerns about the reliability of using CK15 as a marker of hHFSCs [36, 37]. First, integrin $\beta-1$ was found to be coexpressed with CK15 in hHFSCs of bulge [31, 32, 38]. However, later studies showed that integrin $\beta-1$ is not expressed more intensively in the bulge than in the adjacent ORS [34, 39]. Therefore, identification of CK15 should be used with the identification of other markers to identify hHFSCs.

CK19 is another positive marker that has been widely used for the identification of hHFSCs $[31,34,38]$ and is expressed in the anagen and telogen phases of the HF cycle [40]. However, during differentiation, CK19 expression decreases later than CK15 expression, and CK19 is also expressed in ORS cells below the bulge area in an HF [31, 41]. An interesting hypothesis suggests that CK19-positive cells in the bulge region are derived from CK15-positive cells. Only CK15-positive cells are found above the area of the HF in which both CK15-positive and CK19-positive cells are located, and conversely, only CK19-positive cells are located below the area where both CK15-positive and CK19-positive cells are found [42]. Hence, CK15 may be a better marker for identifying hHFSCs.

CD200 is another positive marker commonly used for the identification of hHFSCs [30, 39, 43]. Ohyama et al. successfully obtained HF bulge region stem cells from human HF suspensions using CD200 as a positive marker. In addition, pleckstrin homology-like domain family A member 1 (PHLDA1), also called $\mathrm{T}$ cell deathassociated gene 51 (TDAG51), can prevent apoptosis. A gene microarray analysis showed that PHLDA1 was preferentially located in the bulge cells of the ORS at both the mRNA and protein levels [43]. According to an immunohistochemical analysis, PHLDA1 was also found in the follicle bulge [44]. Nevertheless, PHLDA1 is not specifically expressed in hHFSCs; it can also be expressed in sweat glands and epidermal melanocytes [45]. Furthermore, NFATC1 was found to be expressed in SCs in HF bulges [46]. EpCAM/BER-EP4 is considered to be a useful marker of the telogen optional hair germ [47].

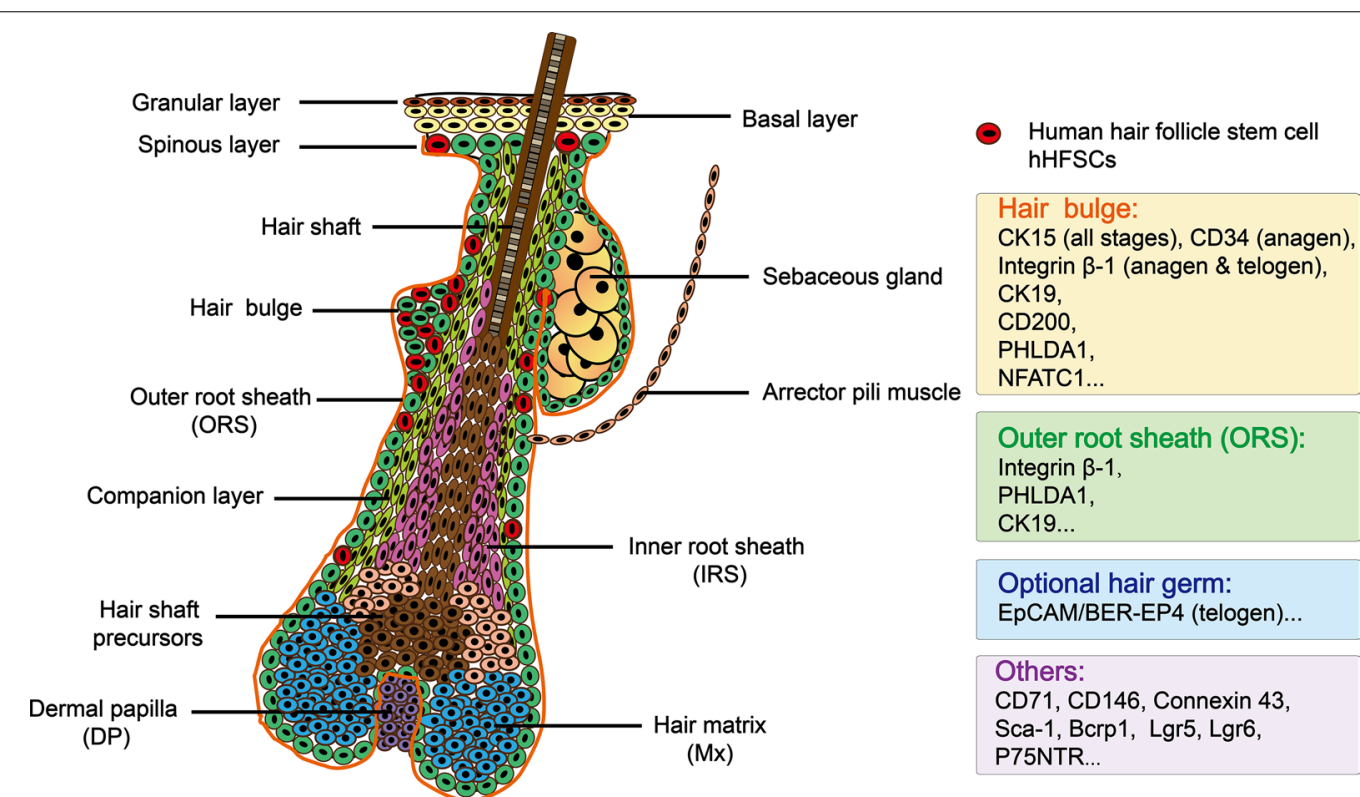

Fig. 1 Structure of the hair follicle and specific markers in HFSCs 
CD34 is a specific positive marker of mouse follicle stem cells $[48,49]$. However, in hHFSCs, CD34-positive cells are expressed below the bulge region and only expressed during the anagen phase. The expression of CD34 in cells of the bulge region in human HFs is low or absent $[43,50]$. CD24-positive cells are not characteristic of HFSCs and are therefore considered to be a negative marker [43]. Lgr6 have been utilized to mark the most primitive epidermal stem cell, and Lgr6 connected with its close relative- Lgr5 has also used as a biomarker of HFSCs [51, 52]. Also, nestin, an intermediate filament protein, could serve as a marker of HFSCs, and also neural stem cell [53]. Cells, located in the HF pluripotent stem cell (hfPS) area (hfPSA), could be labelled with the nestin positive and keratin 15 (K15) $^{-}$negative [53]. Other markers of hHFSCs have been identified, including CD71 [43], CD146 [43], Connexin 43 [34], Sca-1 [54], Bcrp1 [54], and P75NTR [54, 55]. In order to improve the accuracy of detection of HFSCs, recent studies have made use of a combination of a body of markers to identify HFSCs.

Horizontally (in the horizontal direction), the HF consists of the inner root sheath (IRS) the companion layer, and the outer root sheath (ORS). The structure of the hair follicle is formed by some of the contents: dermal papilla (DP) as dermal part of the hair follicle; inner root sheath (IRS) as the inner channel of the hair shaft which locates various of stem cells such as HFSC; hair shaft: emerging as a hair from the skin surface; outer root sheath (ORS): the external layer of the HF. A prominent bulge between the APM of the ORS and the duct of the sebaceous gland is considered to be the reservoir of human HFSCs (hHF$\mathrm{SCs})$. Here, the location and multiple markers of HFSCs are shown in the figure.

\section{HFSC functions and applications}

For an in-depth exploration of HFSCs, understanding the functions of HFSCs will contribute to the useful parameters for both further study and clinical applications. On the one hand, HFSCs have the ability to selfrenew and differentiate into ectodermal and mesodermal cell lineages during injury repair, forming abundant and enriched pools of cells involved in repair. HFSCs contribute to tissue homeostasis in HFs [56], and HFSCs can also promote cutaneous wound healing via different pathways, such as through the high expression of SDF- $1 \alpha$ and CXCR4 [57]. In addition, they have the potential to differentiate into many kinds of cells, such as neurons, Schwann cells, melanocytes, keratinocytes, adipocytes, smooth muscle cells, and bone cells [15, $18,58,59]$. Considering this ability, some studies have shown that injection of HFSC exerted a protective influence on middle cerebral artery ischaemia/reperfusion due to the regeneration of neurons and the reduction in infarct volume in rat models [60]. The large capacity for self-renewal and differentiation into most mesodermal and ectodermal cell derivatives makes HFSCs prominent among all SCs. Along with the rapid development of SC technologies, we believe that activating HFSCs may hold promise for the therapy of many kinds of diseases, such as cardiovascular diseases and motor system diseases.

On the other hand, HFSCs can influence multiple other cells or tissues. For example, HFSCs enhanced tissue tensile strength as vascular density increases in an HFSCtreated animal model of burn wounds [61]. In addition, some factors secreted from HFSCs play significant roles in modulating surrounding niche cells. For instance, signals from HFSCs can regulate the surrounding skin vasculature. HFSC-derived Angptl7 transcription is involved in lymphatic dynamics, and HFSCs can remodel the vasculature around the HF by changing Runx1 levels [62, 63]. In summary, HFSCs contribute not only to renewal and reestablishment of HFs but also to the regulation of niche homeostasis.

\section{Signals and signaling pathways in HFSCs}

The fate and functions of SCs related to tissue renewal, regeneration, and development are rigorously controlled by the local microenvironment (also known as the "niche", which is formed by various biomolecules such as cytokines, growth factors and others) via a complex signalling network $[4,64,65]$. Damage and protective factors participate as initiators in these signalling pathways during the development and pathology of HFSCs. Damage inducers include mechanical force, ultraviolet (UV)induced stress, drug-induced stress, hormonal disorders or dihydrotestosterone (DHT) damage (inducing androgenic alopecia), and psychological stress [4, 48, 66, 67]. Protective factors include platelet-rich plasma (PRP), an adequate supply of oxygen and blood, etc. [68]. The regulation of survival and death signalling pathways plays a driving role in the quiescence, activation, differentiation and metabolism of HFSCs, which is fundamental for skin homeostasis, hair repair, and hair growth. We review the major signalling pathways that are activated during the life of HFSCs, including during survival and death.

\section{Molecular mechanisms affecting the survival of HFSCs The Wnt/ $\beta$-catenin pathway}

Wht is in a family of extracellular developmental signalling proteins controlling a myriad of different cellular fates [69]. For example, the activation of $\mathrm{Wnt} / \beta$-catenin can promote the continuation of the process of renewal of various tissues by fuelling SC activity [14]. The canonical Wnt/ $\beta$-catenin pathway is mainly related to a class of Wnt hydrophobic proteins tethered to their cognate 
receptors on the cell membrane, driving a series of transcriptional programmes (Fig. 2). The processes of Wnt pathways are shown and discussed in further detail below.

As early as the 1990s, transgenic mouse studies revealed the diverse roles of Wnt signalling in the specific development of HFs; specifically, de novo follicles were shown to express stabilized $\beta$-catenin in mice, and few follicles were found in mice lacking Lef1 or $\beta$-catenin [70, 71]. With the development of in-depth mechanistic studies, a detailed molecular pathway was shown more clearly both in terms of the activation and inhibition of Wnt signalling. In the absence of a Wnt signal, a multiprotein complex formed by APC, Axin, and GSK3 can target and phosphorylate $\beta$-catenin, leading to excessive cytoplasmic $\beta$-catenin degradation. It has been reported that upregulation of DKK1, IWP2, or sFRP1 (a specific negative regulator of Wnt signalling) can inhibit accelerated HFSC proliferation and differentiation into follicular components $[6,72,73]$. Normally, the bulge is observed in a Wnt-inhibited environment, as microarray data have shown that the genes encoding putative Wnt inhibitors (e.g., sFRP1, Dkk3, and Wif) are upregulated and that the genes encoding Wnt promotors (e.g., Wnt3 and $W n t 3 a)$ are downregulated [23]. However, this quiescence needs to be disrupted at certain times through a. Wnt signaling (rerpession)

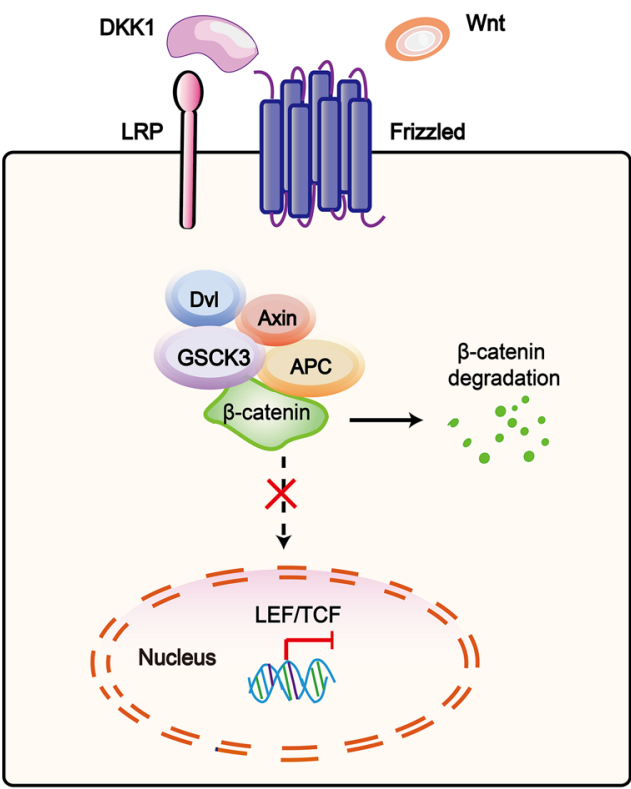

\section{b. Wnt signaling (activation)}

Wnt

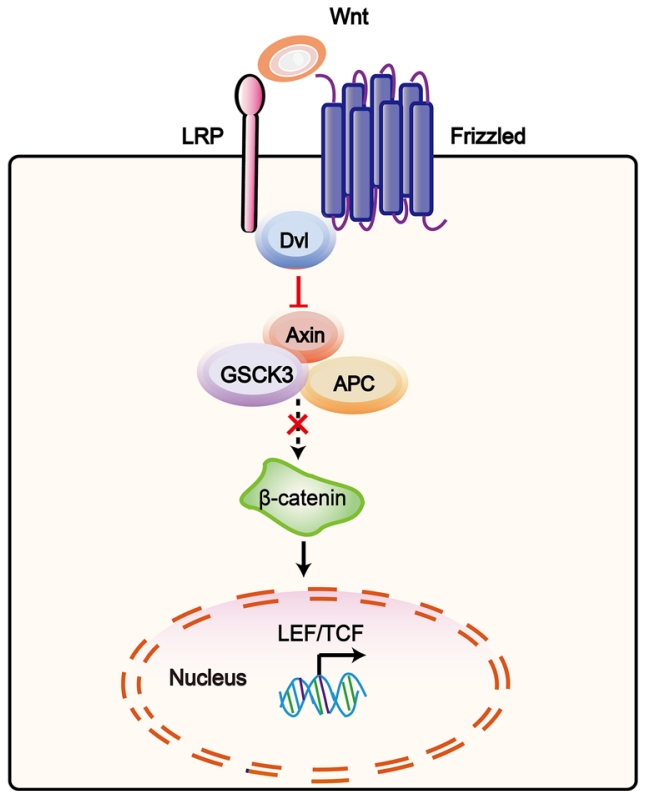

\section{c. Gradient of Wnt signaling and HFSC}

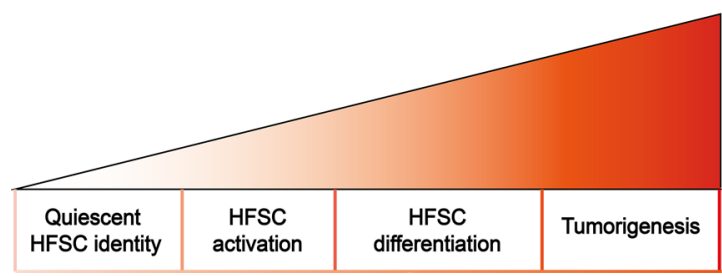

Low gradient: required in telogen

High gradient: hair growth and shaft differentiation

Excessive gradient: leading to pathology like tumor

Fig. 2 Molecular mechanisms and functions of the Wnt/ $\beta$-catenin signalling pathway in HFSCs. a In the absence of a Wnt signal for the binding of Wnt inhibitors (e.g., sFRP1, Dkk3, or Wif), a multiprotein complex is formed with APC, Axin, and GSK3, which can target and phosphorylate $\beta$-catenin, leading to excessive cytoplasmic $\beta$-catenin degradation. $\mathbf{b}$ Once Wnt binds to Frizzled and lipoprotein receptor-related protein (Lrp5/6 receptors), the activated receptor complex induces recruitment of certain key components, such as Dvl, which results in the destruction complex disassembling, to prevent $\beta$-catenin degradation. Accumulated and stabilized $\beta$-catenin is translocated to the nucleus, where it can bind transcription factors (e.g., LEF/TCF family) to promote the expression of target genes, such as Axin2, LEF1 and Lgr5. c Wnt signalling shows a close association with HFSCs in quiescence, activation, and differentiation and even in Wnt-induced tumorigenesis. The T-shaped lines indicate inhibitory interactions involved in this pathway, and the solid arrows indicate activating interactions 
bulge SCs expressing a number of surface Wnt signal receptors (e.g., frizzled 2/3/7) to enable a combination of Wnt signals [23].

Once Wnt binds to Frizzled and lipoprotein receptorrelated protein (Lrp5/6 receptors), the activated receptor complex induces recruitment of certain key components, such as Dvl (Disheveled), which results in the destruction complex disassembling, preventing $\beta$-catenin degradation. Wnt10b, a canonical Wnt ligands, has been shown to be upregulated in the secondary hair germ region, where the expression of $\beta$-catenin is overregulated upon anagen phase onset, highly expressed in the middle anagen phase, and expressed at low levels in the catagen and telogen phases, whereas the absence of $\beta$-catenin signalling in the skin leads o inhibited hair regeneration and permanent hair loss [70, 74]. Wnt10b functions as a major activator, and Wnt10b is an activator that regulates HFSC expression during the telogen-anagen phase transition [75].

The mechanism that stabilizes $\beta$-catenin during HFSC development leads to a change in the telogen-to-anagen transition of the hair cycle. Accumulated and stabilized $\beta$-catenin is translocated to the nucleus, where it can bind transcription factors (e.g., LEF/TCF family) to promote the expression of target genes, such as Axin2, LEF1 and $L g r 5$, resulting in the promotion of TAC conversion, and is replaced in activated cells during de novo follicle generation (Fig. 2) [76, 77]. Some groups have reported that activation of hair regeneration occurs precociously upon the upregulation of stabilized $\beta$-catenin expression in the telogen phase [77]. Additionally, a microarray assay showed transgene expression changes (e.g., in Sox4, biglycan, and cyclin D2 (Ccnd2)) in telogen- or anagenphase SCs isolated from $\beta$-catenin-mutant or wild-type follicles, which may promote hair cycle progression [77]. This signalling seems to emanate from the DP in close proximity to the bulge. Consistent with this notion, some studies have found that exosomes derived from DP cells can promote the anagen phase of HFs [78].

Overall, the Wnt/B-catenin pathway has been considered a central signalling pathway leading to the transition of HFs from the telogen to anagen phase, which is closely related to the physiology and pathology of other skin components, such as HF morphogenesis, hair shaft differentiation, and pathological changes (e.g., pilomatricoma tumour induction) [79-81].

\section{The Sonic hedgehog (Shh) pathway}

The Shh pathway plays a driving role in regulating developmental patterning and proliferation in multiple tissues, including HF tissue $[82,83]$. This connection with HFs can be traced to two direct functions of Shh: 1) improving quiescent SC proliferation and 2) regulating the dermal factors that induce TAC expansion [7]. Quiescent SCs begin to express Shh, while primed SCs generate TACs, and it has been found that the TAC pool is reduced in the absence of Shh signalling [7].

In addition to the Wnt pathway, the development of HFSCs is also linked to Shh signalling, as shown in Fig. 3. In the Shh signalling pathway, Shh induces the release of inhibition of Smoothened (Smo, a G protein-coupled receptor (GPCR)-like protein). Subsequently, Smo can translocate into the membrane and initiate the activation and translocation of Gli into the nucleus, allowing the transcription of target genes (e.g., Ptch and Gli1) forming a feedback loop in this pathway [84-86]. When the ligand Shh does not bind to its receptor Patched (PTCH), this cascade reaction is aborted because Gli is sequestered in the cytoplasm via its interaction with suppressor of fused homologue (Sufu, one of the crucial inhibitors during Shh signalling) [87]. In other words, $\mathrm{PTCH}$ is an inhibitor leading to repression of Shh pathway activation, whereas basal cell carcinoma (BCC), featuring frequent loss of PTCH expression, can cause constitutive activation of the Shh pathway $[88,89]$. Shelby et al. found that multiple HFSC populations readily develop into BCC-like tumours in Ptch1-deleted mice [88], and Kasper et al. reported that more than $90 \%$ of human BCCs are thought to be caused by loss of PTCH1 [90]. Additionally, overexpression of Shh, Smo, or Gli1/2 has been identified during BCC development [91, 92]. Interestingly, HFSCs can also emerge as regulators through the Shh signalling pathway during the development of tissue, which in turn controls HFSC regeneration. HFSCs secrete Shh to direct the formation of the APM-sympathetic nerve niche, forming form a dual-component niche for HFSCs [8].

Shh signalling enriches the pathways activated in HFSC development. However, it remains unclear how signalling and cell diversity function during the hair cycle. Both signals form a bud (a hair germ), as it still occurs in the absence of Shh signalling [93].

\section{The Notch pathway}

During the maintenance of self-renewal in multiple tissues, Notch signalling is closely related to the promotion or suppression of cell proliferation, failure of differentiation programmes, or cell fates. Additionally, many studies have reported a connection between Notch signalling and hair health and hair-related diseases [14]. For example, upregulated and active Notch1 has been found in basal and suprabasal cells in sebaceous glands during the early stage of epidermal stratification; a reduction in the number of HFs occurs in the absence of Notch1 signalling; and Notch1-3 have been identified in differentiating HF cells [94-96]. Aiming to explain how Notch signalling acts in the hair cycle, further research has focused 
a. Shh signaling (rerpession)

Shh

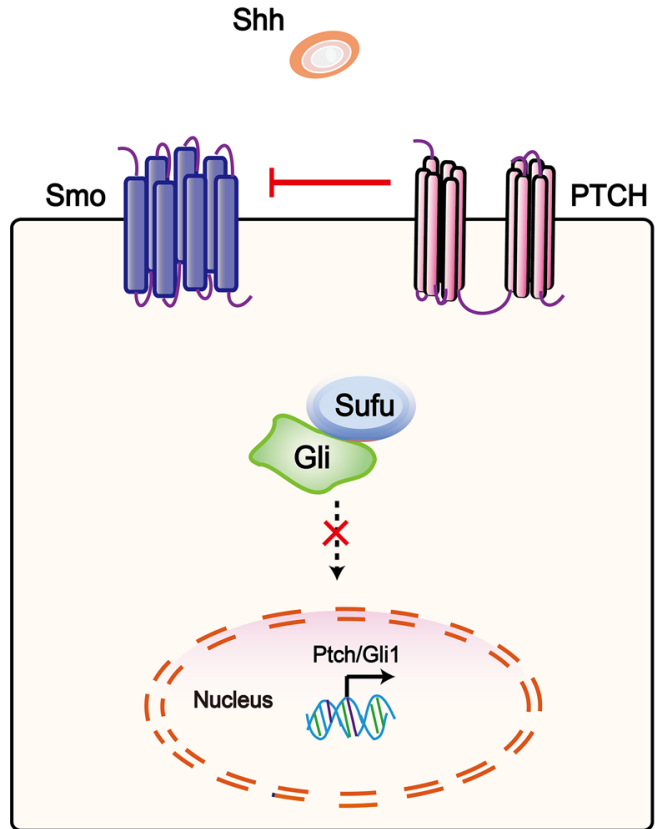

b. Shh signaling (activation)

Shh

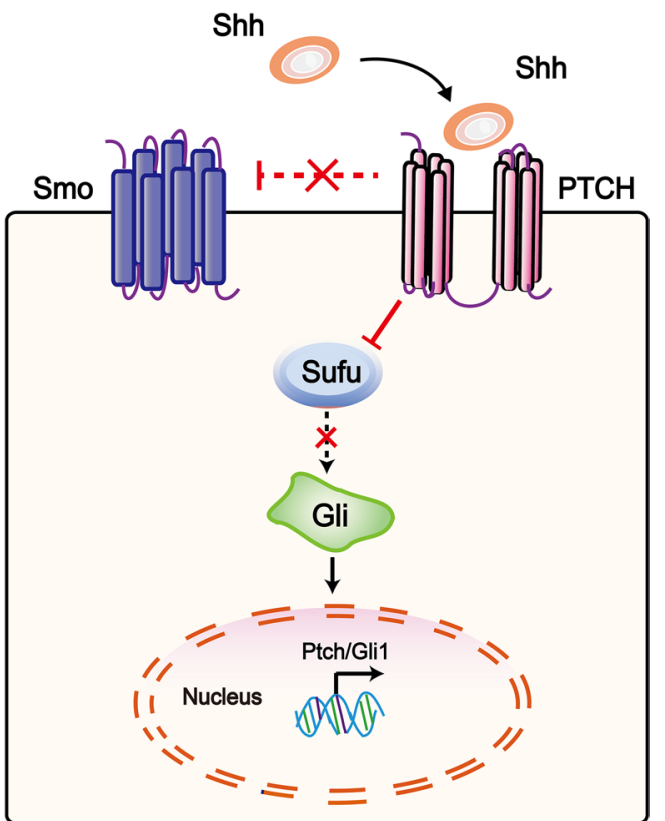

Fig. 3 The Shh signalling pathway in HFSCs. a In the absence of Shh, the complex consisting of Gli and Sufu cannot form, preventing the transcription of the target genes. $\mathbf{b}$ In the Shh pathway, Shh induces the release of Smo inhibition. Then, Smo can translocate into the membrane and initiate the activation and translocation of Gli into the nucleus, allowing the transcription of target genes (e.g., Ptch and Gli 1), creating a feedback loop in this pathway. When the Shh ligand does not bind to its receptor, PTCH, this cascade is aborted, and Gli is sequestered in the cytoplasm via the interaction with suppressor of fused homologue (Sufu, one of the crucial inhibitors of Shh signalling). The T-shaped lines indicate inhibitory interactions involved in this pathway, and the solid arrows indicate activating interactions

on Notch signalling in the bulge SC niche to influence SC maintenance and activation.

Similar to the signalling mentioned above, the Notch pathway also contributes to a certain protein translocating to the nucleus and activating downstream target genes to affect cellular metabolism and growth (shown in Fig. 4) [97]. First, a fully functional Notch receptor binds to a ligand (Dll1-4 or Jag1-2) presented by a neighbouring cell. Once induced, the conformational change of the receptor exposes the recognition site to cleavage by ADAM (a disintegrin and metalloprotease) and $\gamma$-secretase, which leads to the release of the active Notch intracellular domain (NICD). A high level of Notch ligand family member-Jagged 1 (Jag1), which induces the activation, proliferation and differentiation of HFSCs in newly generated HFs in the hair cycle, was identified in Tregs $[9,10]$. Then, NICD is translocated to the nucleus, leading to the formation of a tri-protein complex, consisting of the DNA-binding CSL complex (consisting of CBF1/RBPjK/Su(H)/lag-1)/additional coactivators (CoA)/mastermind (MAM), which induces the transcription of target genes. Conditional disruption the mouse RBP-J gene can cause hair loss and epidermal cyst formation via the aberrant differentiation of RBP-deficient HFSCs [98].
Without the activation of Notch signalling, the NICD does not enter the nucleus, and CSL might connect with ubiquitous corepressor (Co-R) proteins and histone deacetylases (HDACs) to repress target gene transcription. Interestingly, Notch associated with cofactor RBP-J can also function in HFSCs to suppress downstream genes such as retinoid metabolic process genes, which reveals a previously unknown role of Notch signalling in regulating metabolites in HFSCs [99].

A number of studies have shown Notch signalling in HF morphogenesis and gradually revealing this Notch signalling pathway in HFSCs, attracting the interest of scientists seeking to explain the mechanism of the Notch signalling axis, and further research is needed to determine the complex downstream genes regulated by Notch signalling in HFSCs, the association of Notch with other signalling molecules in co-networks in HFSCs that influence the hair cycle, and to determine whether these proteins and/or genes are stable and effective targets for clinical application.

\section{Bone morphogenetic protein (BMP) pathway}

HFSCs, particularly TAC formation in response to BMP signalling during a specific period of the hair cycle, 


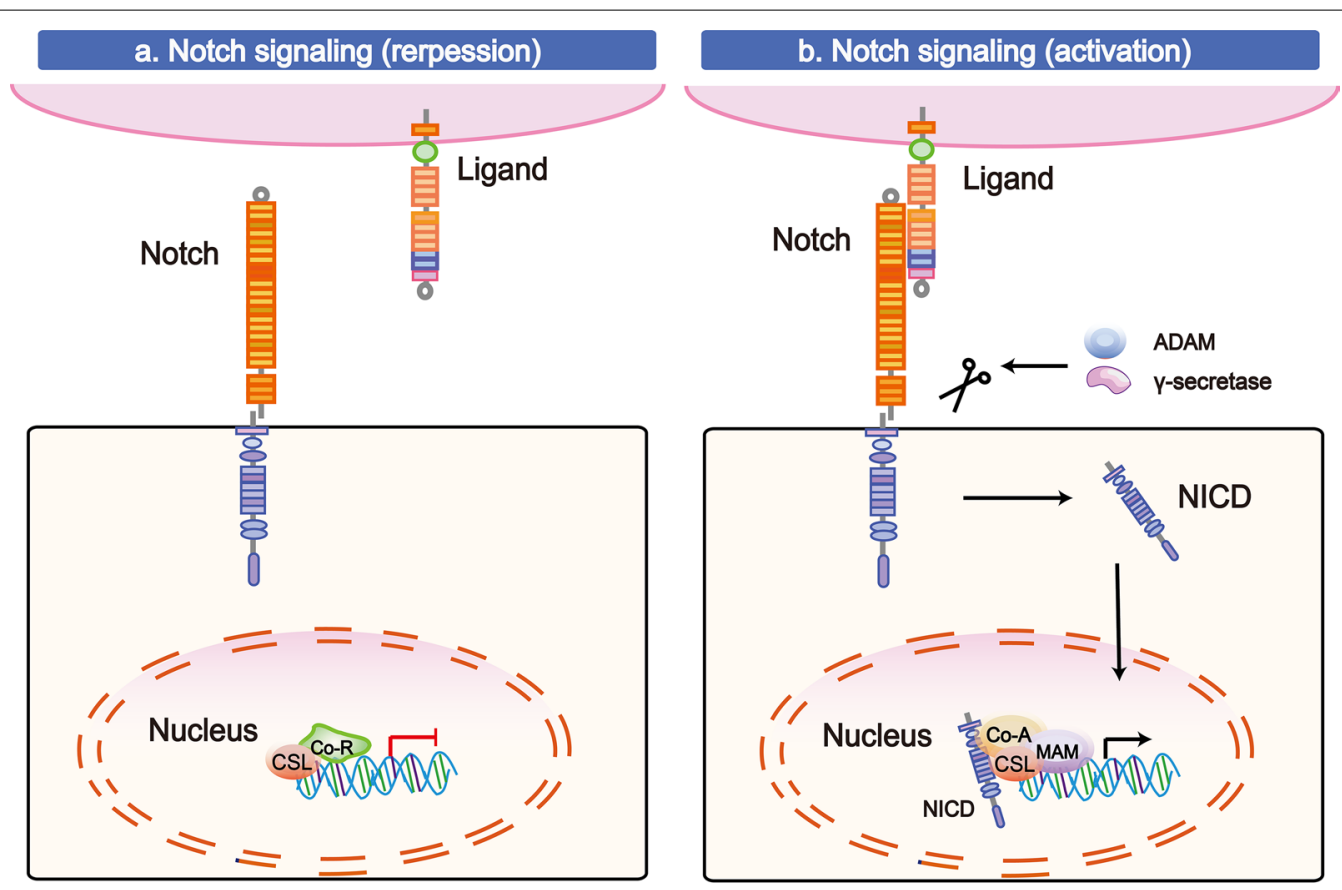

c. Notch signaling in HFSC
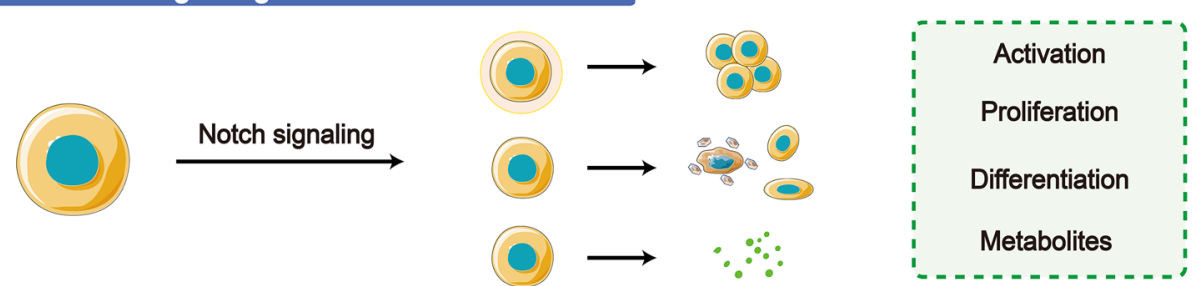

Fig. 4 The Notch signalling pathway in HFSCs. a Without the activation of Notch, the NICD does not enter the nucleus, and CSL might connect with ubiquitous corepressors (Co-R) and histone deacetylases (HDACs) to repress target gene transcription. $\mathbf{b}$ In the Notch pathway, a fully functional Notch receptor binds to a ligand (DII1-4 or Jag1-2) presented by a neighbouring cell, resulting in a conformational change of the receptor that expose the recognition site for cleavage by ADAM and $y$-secretase, leading to the release of the active Notch intracellular domain (NICD). Subsequently, NICD is translocated to the nucleus, leading to the formation of a complex, the DNA-binding protein CSL (CBF1/RBPjk/Su(H)/ lag-1)/additional coactivators (Co-A)/mastermind (MAM), which induces the transcription of target genes. $\mathbf{c}$ Notch signalling plays a vital role in the activation, proliferation, deafferentation of HFSCs and metabolite generation. The T-shaped lines indicate inhibitory interactions involved in this pathway, and the solid arrows indicate activating interactions

exhibit self-regulated proliferation and differentiation [100]. BMPs, as a member of the TGF- $\beta$ superfamily, exhibits biological activity after secretion and binding to a transmembrane heterodimeric receptor complex (formed by BMPR-I and BMPR-II) [83]. BMP signalling is a key mechanism that modulates or reinforces the quiescence of HFSCs upon self-renewal, maintains cell identity and is required for TAC generation [101, 102]. However, reduced or inhibited BMP signalling can also activate HFSCs; a loss of Bmpr1a in mice caused aberrant activation of quiescent HFSCs [101, 103, 104]. The expression of Noggin (a specific BMP antagonist) is upregulated upon mesenchymal condensation, while
BMP is downregulated in the early stage of the hair cycle, which is required for HF activation and morphogenesis [13]. Recently, microRNAs (miRNAs, miRs) have been shown to be inhibitors of BMP signalling, and it has been reported that miR-29a/b1 can negatively regulate Bmprla by binding to the 3'-UTR of Bmprla [104].

The detailed mechanism of the BMP pathway is graphically presented in Fig. 5 and explains as follows: Upon initiation of the BMP pathway, a BMP dimer connects with a specific receptor. Then, the dimer phosphorylates and activates R-Smad (Smads 1/5/8) and subsequently associates with the co-Smad partner Smad 4 [101]. Finally, the complex formed by R-Smad/co-Smad is translocated into 


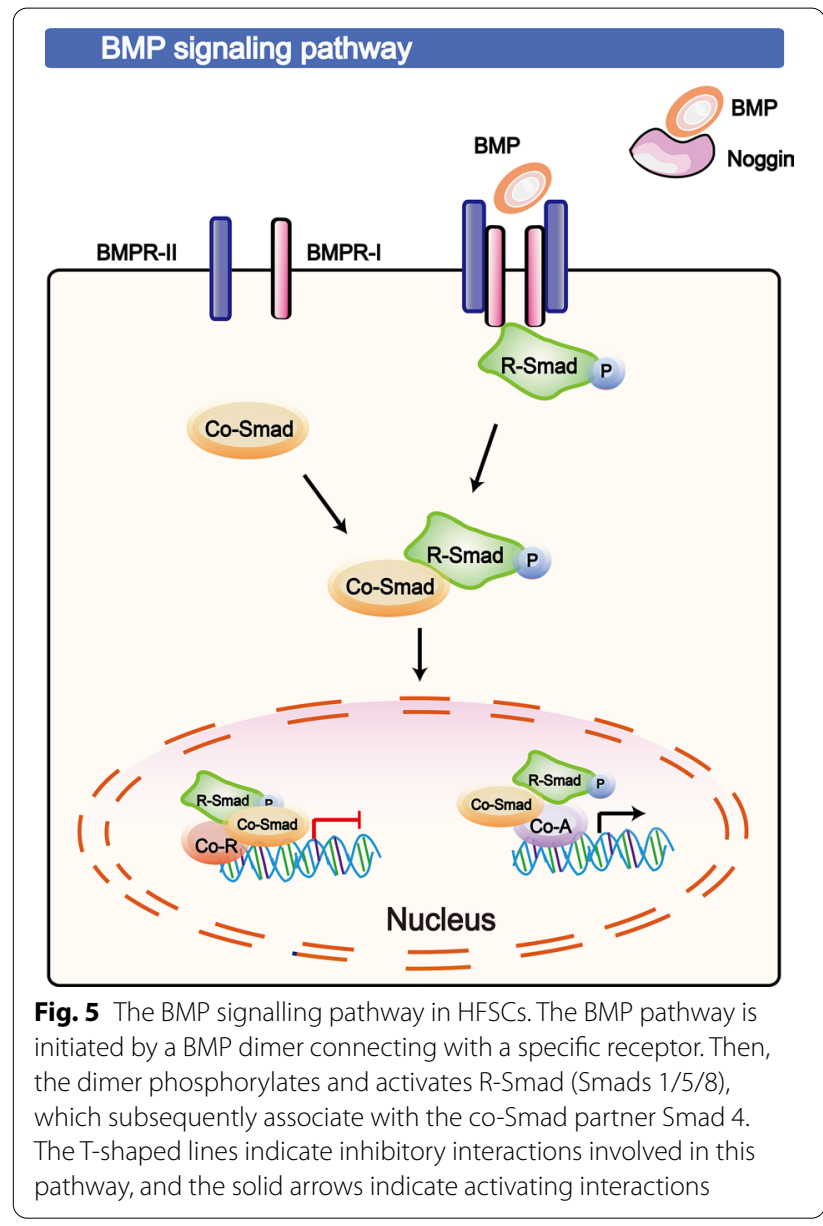

the nucleus, resulting in the transactivation of its target genes. However, the detailed mechanisms and biological functions of these downstream targets are still being discovered, and BMP signalling is likely to be involved in HFSCs in the HF cycle and HF morphogenesis. To gain insight, the Kandyba group utilized the keratin 15 (K15) promoter, driving inducible Cre recombinase to ablate Bmprla in telogen-phase HFSCs in the bulge and hair germ (HG). Then, this group found 16 upregulated RNAs (e.g., Wnt7a/7b/16) and 80 downregulated mRNAs (e.g., BMP6, FGF18 and Wnt inhibitor DKK3), which suggests a significant role for BMP in HFSCs closely related to the HF cycle [101, 105].

In addition, Noggin/BMP signalling has also been found to play vital roles in lung alveolar stem cells and neural stem cells $[106,107]$. Other inhibiting signalling, such as inhibition of the epidermal growth factor receptor (EGFR), contributes to the delicate balance between activation and quiescence during the development of HFSCs. Data have shown that in EGFR-knockout follicles, an elevated level of $\mathrm{Wnt} / 6 / 7 \mathrm{~b} / 10 \mathrm{a} / 10 \mathrm{~b}$ and 16 transcripts and hyperactivation of $\beta$-catenin signalling [73].

\section{The crosstalk between survival signalling pathways}

Each signalling pathway discussed thus far has emerged as a regulator involved in the fate of HFSCs. Furthermore, a body of evidence suggests that more than one of these pathways is active in HFSCs, either at the same time or in different periods [93]. And a figure described crosstalk among the survival signalling pathways has shown in Fig. 6 Regarding the established links to both Wnt and Shh signalling, two interactive pathways have been described: (1) downstream glycogen synthase kinase-3 $\beta$ (GSK-3 $\beta$ ) forms an complex inhibiting the Wnt and Shh morphogenetic pathways [108]; Notably, GSK3 $\beta$ is also an inhibitor of Notch signalling [109]. In contrast to other pathways, GSK3 $\beta$ contributes to Wnt signalling in an indirect way, as its phosphorylation at the $\mathrm{N}$-terminal domain of $\beta$-catenin is mediated by the SC factor/ ubiquitin/proteasome pathway, which is a key factor in Wnt signalling [110]. Once GSK3 $\beta$ is overexpressed, the pathways are inhibited, as is the differentiation of HFSCs; through one of the Shh positively regulated downstream genes, which can inhibit Wnt ligands and/or their receptors (namely, secreted frizzled-related protein-1 (sFRP-1)) or promote the Wnt process via Gli- and Foxfamily, leading to either Wnt-Shh antagonistic or synergetic effects in the HFSCs [111]. Although both signals occur within the bud, the Shh pathway has been found to be genetically downstream of the Wnt pathway and is still activated in the absence of Shh; however, hair buds do not progress further $[93,112]$.

Some molecular agents may establish the connections within this network in HFSCs or contribute to the development of hair. Dlx3 is a homeobox transcription factor that is not only activated downstream of Wnt through Lef targeting but is also the cause of lost BMP signalling. In the telogen phase bulge, HFSCs are inhibited to preclude reinitiation of the HF growth cycle upon the ablation of Dlx3 expression associated with Wnt signalling and a loss of BMP signalling [113]. The expression of Shh and Sox4 (a downstream target genes in the Wnt signalling pathway), characteristic of quiescent bulge cells and/ or their early proliferating progeny, was upregulated after BMP pathway inhibition, controlling HFSC differentiation [70]. Lef $1 / \beta$-catenin-mediated transcription in Wnt signalling is elevated in the absence of BMPR1A [114]. Moreover, dermal Shh can upregulate dermal noggin expression, which is a potent inhibitor of BMP signalling that helps to counteract BMP-mediated $\beta$-catenin inhibition [83].

Remarkably, an increasing number of signalling pathways related to HFSCs have been identified (shown in Table 1), and this co-network may involve these signalling pathways. For example, Notch signalling can suppress TGF- $\beta$ and activate the Kit ligand to maintain an 


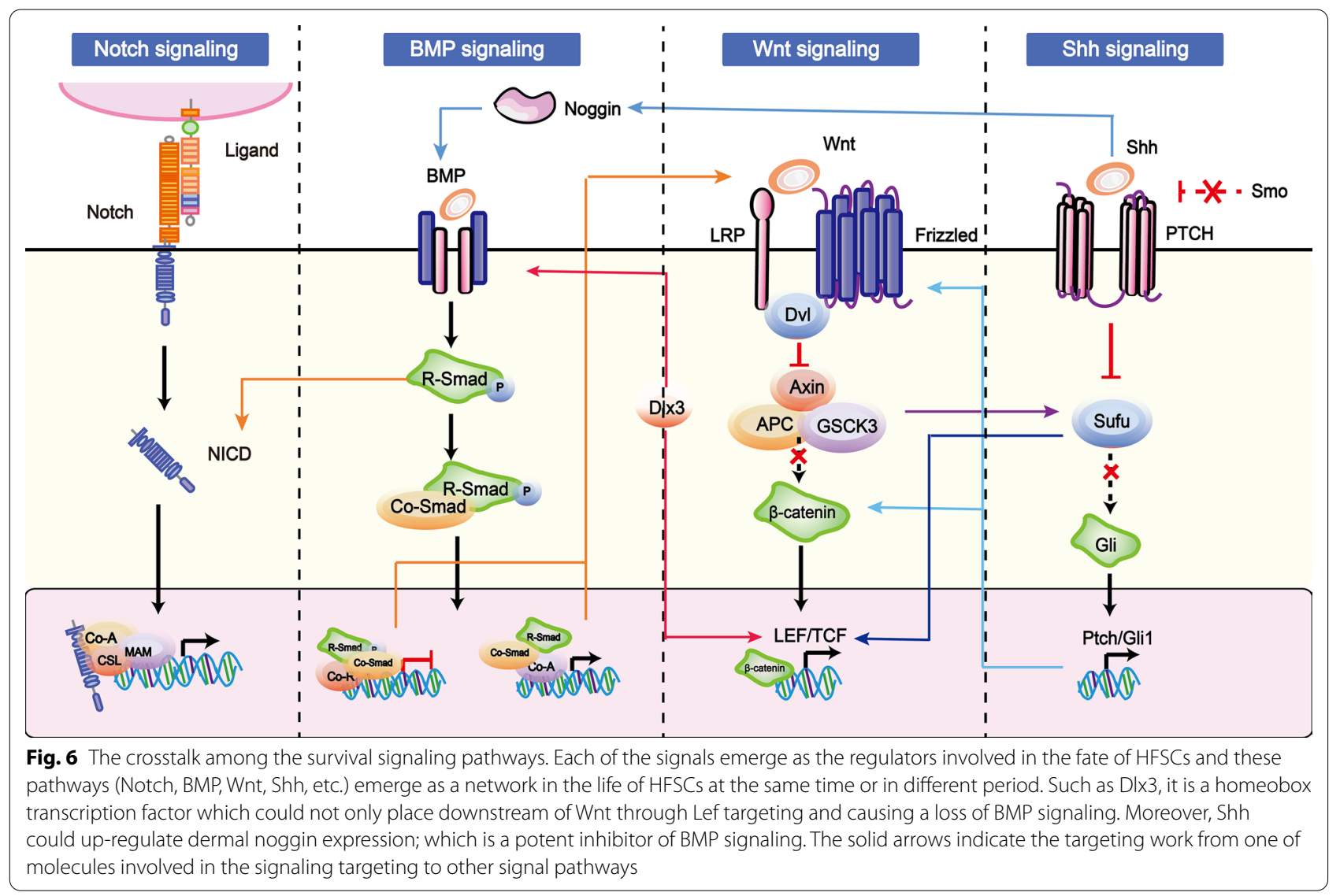

optimal matrix-proliferating environment for SCs [115, 116]. Moreover, mice lacking EGFR show overexpression of Wnts by upregulating the Wnt antagonist sFRP1, which coordinates the delicate balance between proliferation and differentiation during HFSC development [73]. Overall, the interactions are complex and involve multiple networks, not one crucial pathway, whose balance is vital to the fate and development of HFSCs.

\section{Molecular mechanisms during HFSC death}

During the development of biological systems, tissue structures and organs are repaired and sculpted by the removal and addition of constituent cells via the alternative processes of controlled cell death (also known as regulated cell death, RCD, including apoptosis, autophagy, necroptosis, pyroptosis, and ferroptosis) and cell recruitment $[140,141]$. In inferior HFs, RCD may be a central element of growth cycle progression and regression of each hair cycle [142]. Moreover, RCD occurs extensively in HFs during skin disorders in alopecia. However, what role does RCD play in HFs? Which cell types are prone to cell death [143]? Which genes can be targeted to treat this disorder? To obtain answers to these questions, further research is needed, and the role of RCD in HFSCs has garnered attention for the pathological and physiological processes in hair $[144,145]$. It has been reported that the degree of HFSC damage determines whether alopecia is reversible [143]. The targets involved in RCD for improving HFSCs or improving HFSC-based therapy may provide novel strategies for skin-related diseases such as alopecia, skin cancer, skin inflammation, and skin wound healing.

\section{Apoptotic pathways}

To date, an emerging body of evidence has highlighted an important role for apoptosis of HFSCs [142, 146, 147]. For example, DNA damage caused by ionizing radiation causes premature senescence of HFs, which is associated with apoptosis of cells outside and inside the HFSC population [12]. A brief relevant review on the role of RCD in HFSCs is presented.

Apoptosis is a key RCD in which reversible cell damage is blocked by small-molecule inhibitors and a regulated process of cell death is initiated by multiple stresses, including DNA damage caused by radiation, reactive oxygen species (ROS), viral infection, and so on [148]. According to the inducing signals, the apoptotic pathway has been categorized into two forms: the 
Table 1 The survival signaling pathway in HFSCS

\begin{tabular}{|c|c|c|c|c|c|c|}
\hline $\begin{array}{l}\text { Signaling } \\
\text { pathway }\end{array}$ & Axis & Key molecule & $\begin{array}{l}\text { Regulation } \\
\text { (up/down) }\end{array}$ & Target genes & Effects & Ref \\
\hline \multirow[t]{5}{*}{ Wnt } & Wnt/ $\beta$-catenin & Wnt & up & Cyclin D1 & $\begin{array}{l}\text { Initiating DNA synthesis and leading to the } \\
\text { increase of viability of HFSCs }\end{array}$ & {$[117]$} \\
\hline & & & & Myc & $\begin{array}{l}\text { Leading to the activation of HFSCs by increasing } \\
\text { lactate production, and also increasing the viabil- } \\
\text { ity of HFSCs }\end{array}$ & {$[117,118]$} \\
\hline & & & & Axin2 & $\begin{array}{l}\text { Contributing to proliferation, migration of dermal } \\
\text { papilla and promoting HFs growth }\end{array}$ & [119] \\
\hline & & & & Lef1 & $\begin{array}{l}\text { Activating target gene expression, promoting the } \\
\text { activation, proliferation, and differentiation of } \\
\text { HFSCs, increasing Shh level by leading to the } \\
\text { downregulation of E-cadherin, and transmitting } \\
\text { the early Wnt signals along with } \beta \text {-catenin }\end{array}$ & {$[6,83,120]$} \\
\hline & & & down & $D / \times 3$ & $\begin{array}{l}\text { Leading to enhanced proliferation and delayed } \\
\text { regression, since it is essential in hair morpho- } \\
\text { genesis, differentiation and cycling programs, } \\
\text { and also leading to the loss of BMP signaling }\end{array}$ & [83] \\
\hline \multirow[t]{4}{*}{ Shh } & Msi2-Shh-Gli1 & $\mathrm{SHH}$ & up & Gli1 & $\begin{array}{l}\text { Leading to HFSCs proliferation and differentiation, } \\
\text { and inducing HFs neogenesis and hair placode/ } \\
\text { germ formation }\end{array}$ & {$[3,121]$} \\
\hline & & & & Ptch1 & $\begin{array}{l}\text { Activating Gli1 transcription factors and leading to } \\
\text { HFSCs proliferation and differentiation }\end{array}$ & [7] \\
\hline & & & & Cyclin D1, Cyclin D2 & $\begin{array}{l}\text { Inducing the activation of HFSCs and leading to } \\
\text { the increase of viability of HFSCs }\end{array}$ & {$[7,117]$} \\
\hline & & & & Sox9 & $\begin{array}{l}\text { Being required for } \operatorname{SOX} 9(+) \text { cell specification to } \\
\text { HFSCs, leading to the production of Merkel cells } \\
\text { in hair placode and maintaining the growth of } \\
\text { HFs after morphogenesis }\end{array}$ & {$[122,123]$} \\
\hline \multirow[t]{3}{*}{ Notch } & & NICD & up & Hey 1 & Leading to HFSCs proliferation & {$[99]$} \\
\hline & & & & Hes1 & $\begin{array}{l}\text { Replenish HFSCs in order to maintain the hair cycle } \\
\text { homeostasis and leading to the activation of the } \\
\text { secondary hair germ }\end{array}$ & {$[124]$} \\
\hline & & & & Hes 5 & Reducing HFSCs migration and clonogenicity & {$[125]$} \\
\hline \multirow[t]{4}{*}{ BMP } & & BMPR & up & PTEN & $\begin{array}{l}\text { Inducing autophagy to facilitate HFSCs differentia- } \\
\text { tion, inhibiting HFs hyperplasia and reducing the } \\
\text { risk of tumorigenesis }\end{array}$ & {$[126,127]$} \\
\hline & & & & bHLH & $\begin{array}{l}\text { Being able to encode ID proteins as mediators of } \\
\text { HFSCs quiescence }\end{array}$ & [128] \\
\hline & & & down & Wnt7b & $\begin{array}{l}\text { Leading to the disrupted HF cycling which } \\
\text { manifests a shortening growth phase, premature } \\
\text { catagen onset and shortening hair coat produc- } \\
\text { tion with low-level expression of HFs differentia- } \\
\text { tion markers }\end{array}$ & [129] \\
\hline & & & & Lhx2 & Leading to the delay of HFSCS activation & {$[83]$} \\
\hline \multirow[t]{4}{*}{ TGF- $\beta$} & TGF- $\beta /$ smad & TGF- $\beta$ & up & Wnt & Contributing to promotion of cells cycle for HFSCs & {$[117]$} \\
\hline & & & & $\beta$-catenin & $\begin{array}{l}\text { Promoting the HFSCs proliferation and differentia- } \\
\text { tion, and exerting long-term homeostasis of skin } \\
\text { epithelia }\end{array}$ & {$[117,120]$} \\
\hline & & & & pSmad2 & $\begin{array}{l}\text { Promoting the transition between telogen and } \\
\text { anagen }\end{array}$ & [130] \\
\hline & & & & Tmeff1 & $\begin{array}{l}\text { Lowering the BMP threshold for HFSCS activation } \\
\text { by mediating the inhibited effect of TGF- } \beta 2 \text { on } \\
\text { BMP signaling, and contributing in HFSCs activa- } \\
\text { tion during the telogen to anagen transition }\end{array}$ & [130] \\
\hline
\end{tabular}


Table 1 (continued)

\begin{tabular}{|c|c|c|c|c|c|c|}
\hline $\begin{array}{l}\text { Signaling } \\
\text { pathway }\end{array}$ & Axis & Key molecule & $\begin{array}{l}\text { Regulation } \\
\text { (up/down) }\end{array}$ & Target genes & Effects & Ref \\
\hline \multirow[t]{5}{*}{ EGFR } & TGF- $\mathrm{a} / \mathrm{EGFR}$ & EGFR & up & TGM & $\begin{array}{l}\text { Leading to the differentiation of suprabasal-like KC } \\
\text { and promoting cornified envelope formation }\end{array}$ & [131] \\
\hline & & & & $\mathrm{Flg}$ & $\begin{array}{l}\text { Leading to the differentiation of HFSCs and con- } \\
\text { tributing to the epidermal barrier function }\end{array}$ & [132] \\
\hline & & & down & Keratin 1 & Leading to the differentiation of suprabasal-like KC & [131] \\
\hline & & & & Loricrin & Leading to the differentiation of suprabasal-like KC & [131] \\
\hline & & & & Wnt $4,6,7 b, 10 a, 10 b$ & $\begin{array}{l}\text { Being essential to restrain proliferation and sup- } \\
\text { port HFSCs numbers and their quiescence by } \\
\text { influencing Wnt signal pathway }\end{array}$ & [133] \\
\hline \multirow[t]{5}{*}{ AKT } & PI3K/AKT & AKT & up & TGF- $\beta 2$ & $\begin{array}{l}\text { Leading to the activation of TGF- } \beta \text { mediated } \\
\text { transcription in HFSCs and inducing HFSCs to } \\
\text { proliferate during the quiescent period of the } \\
\text { hair cycle }\end{array}$ & {$[130,134]$} \\
\hline & & & & IGFBP-3, 4, 24, and 25 & $\begin{array}{l}\text { Exerting both growth-inhibitory and -potentiating } \\
\text { effects for HFSCs, and IGFBP4 acting as an inhibi- } \\
\text { tor in the canonical Wnt pathway by directly } \\
\text { interacting with the Wnt receptor to prevent } \\
\text { Wnt3a binding }\end{array}$ & [134] \\
\hline & & & down & IGFRI and IGFR2 & $\begin{array}{l}\text { Expressing a duality of HFSCs including both } \\
\text { growth-inhibitory and -potentiating effects, and } \\
\text { leading to delay in the anagen/catagen switch } \\
\text { among HFs }\end{array}$ & {$[134,135]$} \\
\hline & & & & Fgf18 & $\begin{array}{l}\text { Leading to HFSCs proliferation and hair regenera- } \\
\text { tion }\end{array}$ & {$[6,8]$} \\
\hline & & & & Foxp 1 & $\begin{array}{l}\text { Leading to HFSCs proliferation and hair regenera- } \\
\text { tion }\end{array}$ & {$[8]$} \\
\hline \multirow[t]{5}{*}{ Fox } & & Fox family protein & up & Cdh1 & $\begin{array}{l}\text { Weakening proliferative activity of Bu-HFSCs due } \\
\text { to E-cadherin-mediated inter-SC adhesion }\end{array}$ & [136] \\
\hline & & & & Lhx2 & $\begin{array}{l}\text { Leading to HFSCs activation, maintaining their } \\
\text { characters of regeneration and undifferentiation } \\
\text { in HFs, and also promoting epidermal regenera- } \\
\text { tion }\end{array}$ & {$[83,137-139]$} \\
\hline & & LHX2 & up & Sox9 & $\begin{array}{l}\text { Leading to HFSCs differentiation to promote epi- } \\
\text { dermal regeneration in wound-healing process }\end{array}$ & [138] \\
\hline & & & & $T c f 4$ & $\begin{array}{l}\text { Leading to HFSCs differentiation to promote epi- } \\
\text { dermal regeneration in wound-healing process }\end{array}$ & [138] \\
\hline & & & down & Lgr5 & $\begin{array}{l}\text { Inhibiting the proliferation of HFSCs and disturbing } \\
\text { the cycling of anagen HFs }\end{array}$ & {$[127,138]$} \\
\hline
\end{tabular}

Axin2 Axis inhibition protein 2, bHLH Basic helix-loop-helix, BMP Bone morphogenetic protein, BMPR Bone morphogenetic protein receptor, Cdh congenital diaphragmatic hernia; Distal-less homeobox, EGFR Epidermal Growth Factor Receptor, Fgf fibroblast growth factor, Flg filaggrin, Fox Forkhead box, Foxp 1 forkhead box protein 1, Gli Glioma-associated oncogene homolog, Hes Hairy enhancer of the split, Hey Hairy/enhancer-of-split related with YRPW motif, IGFBP Insulin-like growth factor-binding protein, IGFR insulin-like growth factor, KC keratinocytes, Lef Lymphoid enhancer-binding factor, Lgr leucine-rich repeat-containing G protein-coupled receptor, Lhx LIM homeobox, NICD Notch intracellular domain, Ptch1 Patched-1, PTEN Phosphatase and tensin homolog, SC stem cell, Shh Sonic hedgehog, Sox SRY-related high-mobility-group box, Tcf T-cell factor, TGF- $\alpha$ Transforming growth factor- $\alpha$, TGF- $\beta$ Transforming growth factor-beta, TGM transglutaminase, Tmeff 1 Tomoregulin-1

intrinsic pathway initiated by intracellular stresses (e.g., ROS and DNA damage) and the extrinsic pathway triggered by extracellular cues $[149,150]$. There are various molecules involved in apoptosis (cytochrome $\mathrm{C}$ (cyt C), p53, caspases and Bcl-2). Among these molecules, caspases and Bcl-2 family proteins are the two key members that have also been thoroughly studied in HFSCs (shown in Fig. 7).

\section{The intrinsic pathway of apoptosis}

The intrinsic apoptotic pathway is defined by mitochondrial outer membrane permeabilization (MOMP). Intrinsic stressors upregulate the expression/activation of proapoptotic $\mathrm{B}$ cell lymphoma 2 (BCL-2) proteins and suppress anti-apoptotic BCL-2 family proteins, resulting in MOMP [151]. This outcome suggests that the BCL-2 family is a core element in intrinsic apoptosis $[152,153]$, in which pro-apoptotic BCL-2 proteins (e.g., 


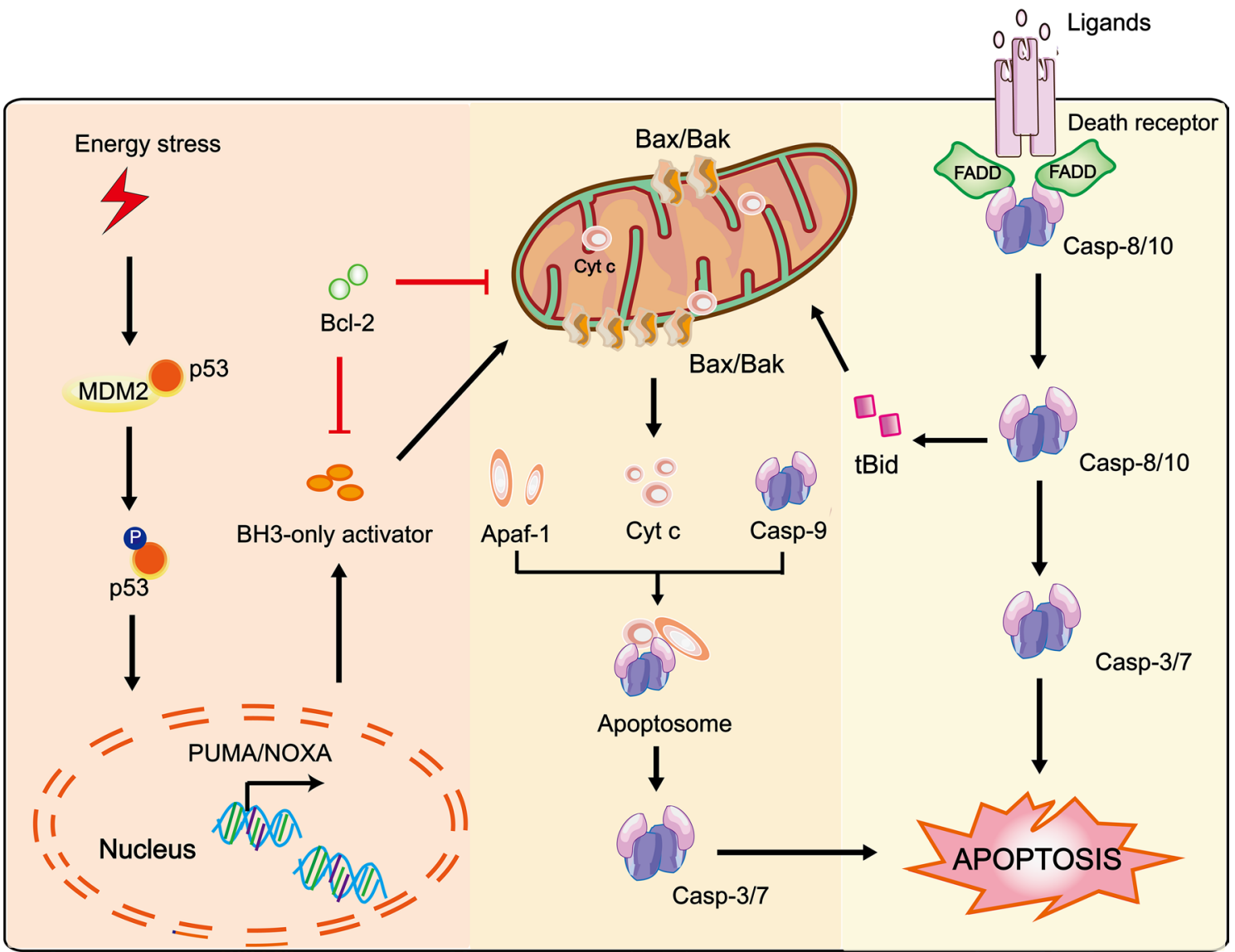

Fig. 7 The apoptotic pathway in HFSCs. There are two apoptotic pathways, namely, the intrinsic pathway initiated by intracellular stresses (e.g., ROS and DNA damage) and the extrinsic pathway triggered by extracellular cues. a Intrinsic stressors upregulate the expression/activation of proapoptotic BCL-2 family members and suppress anti-apoptotic BCL-2 family proteins, resulting in MOMP. Intrinsic stressors can also induce the overexpression of proapoptotic proteins (e.g., NOXA (proapoptotic BH3-only protein, also known as PMAIP1 [phorbol-12-myristate-13-acetate-i nduced protein 1]), p53 upregulated modulator of apoptosis (PUMA), and apoptosis regulator Bcl-2-associated X protein (Bax)) in the p53-based apoptotic pathway, which is induced by the activation and stabilization of p53 through phosphorylation leading to its nuclear translocation, DNA binding and transcriptional initiation. Once MOMP is induced, cyt-c is released from the mitochondrial intermembrane and associates with caspase-9 and Apaf-1 to form apoptosomes, which can activate caspase-3 or caspase-7, causing apoptosis. b The extrinsic apoptotic pathway is triggered by the combination of the tumour necrosis factor receptor (TNFR) family members and specific TNF family ligands, leading to a caspase response. Once bound, TNFR/TNF undergoes a conformational change resulting in the recruitment of Fas-associated death domain (FADD) and subsequently pro-caspases-8 to form the death-inducing signalling complex (DISC). Finally, activated and cleaved caspase-3 leads to the occurrence of apoptosis, with characteristic changes such as phosphatidylserine plasma membrane exposure, DNA fragmentation, and the formation of apoptotic bodies. Remarkably, the intrinsic and extrinsic pathways are connected via the Bid protein. The T-shaped lines indicate inhibitory interactions involved in this pathway, and the solid arrows indicate activating interactions

Bax and Bak) create pores in the outer mitochondrial membrane (OMM) to induce MOMP during apoptosis, while anti-apoptotic BCL-2 proteins inhibit this cascade (e.g., Bcl-2, Bcl-x L, and Mcl-1) [154, 155]. Notably, intrinsic stressors can induce the overexpression of pro-apoptotic proteins (e.g., NOXA (the pro-apoptotic BH3-only protein, also known as PMAIP1 [phorbol12-myristate-13-acetate-induced protein 1]), p53 upregulated modulator of apoptosis (PUMA), and apoptosis regulator Bcl-2-associated X protein (Bax)) in the p53based apoptotic pathway, which refers to the activation and stabilization of p53 by phosphorylation leading to its nuclear translocation, DNA binding and transcriptional initiation [156-159].

This delicate balance of BCL-2 family members contributes to the life of HFSCs. Upon induction of minor damage, HFSCs usually undergo anti-apoptotic progression, while irreversible damage may lead to cell 
elimination through apoptosis [160]. To ensure bulge homeostasis, HFSCs are continuously renewed, with new cells replacing differentiated or/and damaged cells, which are lost after wounding or chemotherapy-induced damage [159]. During extended periods of self-renewal and repair, HFSCs are at high risk for accumulating deleterious mutations. Therefore, they exhibit a powerful ability to resist damage, as indicated by high expression of $\mathrm{Bcl}-$ 2 (an anti-apoptotic gene) and transient stabilization of p53 [160]. A study has shown that IRS, matrix, and ORS keratinocytes undergo apoptosis in the catagen phase, whereas bulge HFSCs escape apoptosis $[1,25]$.

However, an increasing body of evidence indicates that permanent loss of hair regeneration can sometimes occur following the use of busulfan $(\mathrm{Bu})$, etoposide, carboplatin, cyclophosphamide, docetaxel, paclitaxel or other drugs $[161,162]$. These permanent hair loss conditions may be caused by a persistent change in DNA double-strand breaks in HFSCs, mostly in the DNA-replicating $\mathrm{S}$ phase [159]. Strategies to ensure that the damage is restricted to a range that can tolerated and to induce action, such as by triggering the upregulation of BCL-2 family genes to prevent permanent or irreversible damage under different conditions (e.g., population, age, sex), remain to be further researched. Additionally, an in-depth study may reveal a clearer mechanism of apoptosis of HFSCs, which may include an unconventional signalling pathway in HFSCs, similar to other SCs.

Once MOMP is induced, cyt-c is released from the mitochondrial intermembrane and associates with caspase- 9 and Apaf- 1 to form apoptosomes, which can activate caspase- 3 or caspase-7, causing apoptosis [163]. Remarkably, caspases are other pivotal components involved in apoptosis and can be functionally subdivided into two types: initiator caspases (caspase-8/9/10) and effector caspases (caspase-3/6/7) [164-166]. The initiator caspases interact through their large $\mathrm{N}$-terminal pro-domain with a specific adaptor protein, leading to dimerization-induced activation for the cleavage of effector caspases. In contrast, effector caspases can spontaneously dimerize without need for cleaving a pro-domain $[167,168]$. Among these caspases, caspase- 3 is usually utilized as a biomarker for the detection of apoptosis [169]. In HFSCs, higher expression of caspase 3 has been found after irradiation-induced DNA damage [12]. Most important, caspases and $\mathrm{Bcl}-2$ may be targets that regulate the apoptosis for HFSCs. For example, the Jian group revealed that a miR-149-5p inhibitor can suppress the proliferation and trigger the apoptosis of HFSCs, while miR-149-5p can upregulate the expression of $\mathrm{Bcl}-2$ and downregulate caspase 3 , as well as induce anti-apoptotic responses during superior-quality brush hair formation [170].

\section{The extrinsic pathway of apoptosis}

The extrinsic apoptotic pathway is triggered by the combination of the tumour necrosis factor receptor (TNFR) family members and specific TNF family ligands, leading to a caspase response. Once induced, TNFR/TNF causes undergoes a conformational change resulting in the recruitment of Fas-associated death domain (FADD) and subsequently pro-caspases- 8 to form the death-inducing signalling complex (DISC). Finally, activated and cleaved caspase-3 leads to apoptosis, with characteristic changes such as phosphatidylserine exposure to the outer plasma membrane, DNA fragmentation, and the formation of apoptotic bodies [171]. During wound healing, SCs near the wound seem to be awakened and activated to induce proliferation and differentiation needed for tissue repair. The conditional ablation of epidermal caspase- 8 was identified as a cutaneous wound-healing response [172]. Additionally, a series of highly activated HFSCs have been found in Casp8-cKO skin, which suggests a strong association of caspase-8 and HFSCs [173]. Unfortunately, there are many obstacles to in-depth investigation, such as the truncated lifespan of the Casp 8 -cKO mouse ( 20 days).

\section{Other $R C D$ mechanisms}

Moreover, various types of RCD mechanisms have recently been identified along with conventional $\mathrm{RCD}$ mechanisms, such as apoptosis [174]. Moreover, RCDs can play an important role in skin. Among those mechanisms, autophagy, pyroptosis, ferroptosis, and necroptosis have tremendous significance in skin, which may suggest remarkable modulatory impacts on skin-related disease treatment. For example, autophagy, a starvationinduced cellular recycling pathway, is now regarded as a critical event in regulating the skin microenvironment [175]. Phosphatase and tensin homologue (PTEN), an upregulated target of BMP2, is involved in autophagy and can be translocated to the nucleus during oxidative stress, leading to autophagy [176, 177]. In HFSCs, autophagy can promote the differentiation of HFSCs through the BMP2/PTEN axis (a survival pathway, as explained above) [126]. This outcome suggests that the RCD can establish a certain relationship with survival signalling during the life of HFSCs, and cell death may not function as an adverse factor in HFSCs. Pyroptosis, a specific caspase-1-mediated inflammatory form of RCD [178, 179], is closely related to alopecia, and skin defects disrupt autoinhibition [180,181]. Similarly, necroptosis is known as a RIPK1/RIPK3-mediated response [182-188], and the Juan group reported that targeting RIPK1 can prevent skin inflammation damage $[189,190]$. Ferroptosis, an iron-dependent signalling pathway with characteristic iron accumulation and lipid peroxidation [191-193], was 
recently identified as a novel mechanism through a valuable new strategy to efficiently kill human skin melanoma cells [194]. However, there are few studies on the role of these kinds of RCD in HFSCs, which may be a potential approach to improve the microenvironment as well as their function during the life of HFSCs.

Notably, a complex network develops between various survival and death pathways contributing to the development of HFSCs. For example, Notch blockade can promote the proliferation and inhibit the differentiation of hHFSCs, while a significantly lower apoptosis rate has been found [97]. Additionally, it has been reported that, at the end of the telogen phase, HFSC apoptosis is closely associated with the secretion of the Wnt proteins that activate SC, thereby initiating the anagen phase [195]. In the present study, it was discovered that ocu-miR-205 promoted apoptosis and altered the expression of genes and proteins involved in the Wnt, Notch and BMP signalling pathways to promote the transition of HF from the growth phase to the regression and resting phases [196]. Under certain circumstances, cell death may not function as an adverse factor in HFSCs, and autophagy can promote the differentiation of HFSCs through the BMP2/ PTEN axis (a survival pathway mentioned above) [126]. Gradually, studies have directed attention to the vital tole of RCD pathways involved in the development of HFSCs and their connection with survival signalling pathways, which is emerging as a practical and integrated network with signalling co-functions that maintain the niche. However, to discover the mechanisms by which the survival and death pathways are connected and the key molecules involved requires further study, not only to perfect the understanding of the network but also to enhance the applications of therapeutic targets.

\section{Clinical applications based on the survival and death pathways in HFSCs}

With the development of SC engineering, it is critical to know how detailed survival and death signalling is involved in HFSCs during the HF cycle, which will contribute to better clinical guidelines, such as those directed towards improved strategies against cell death for better HFSC-based therapy. From a pragmatic perspective, these signalling pathways provide precise targets for practical use in manipulating HFSCs and even other SCs, enabling repair of pathological tissue or inhibition of abnormal proliferation (shown in Table 2).

\section{Alopecia}

In medical practice, alopecia seems to be an exceedingly prevalent complaint, and the treatment is still difficult and frustrating due to the limited efficacy, long treatment length, and possible adverse side effects. HFSCs play important roles in appropriate hair recovery and regeneration, as indicated in cases of permanent hair loss, such as scarring alopecia, resulting from the irreversible loss of HFSCs [198]. Some alopecia, such as androgenic alopecia (AGA), is reversible because HFSCs are preserved [67]. Therefore, it seems necessary to improve the survival of HFSCs. Based on multiple causes of alopecia including the HFSC damage, a variety of strategies have been utilized for treating against alopecia, including SC-based therapy and biotechnology, platelet-rich plasma (PRP), drug treatment, and also placental extract, peptides, hormones, growth factors and cytokines, androgens and their analogs, stress-serum and chemotherapeutic agents, lipid-nanocarrier, light, electrical and electromagnetic field stimulation, and so on.

SC-based therapy and hair bio-engineering have risen tremendous expectations for alopecia treatment, which provides a new resource and advances hair growth. Clinically, the use of micrografts containing autologous human hair follicle mesenchymal stem cells (HF-MSCs) is considered as a safe and viable treatment alternative against alopecia $[238,239]$. It has been reported that the injection of HFSCs preparations in AGA patients could increase their hair count and hair density up to baseline values [240].

Proponents of PRP approach suggest the benefits for improving the hair growth and increasing in hard/softtissue wound healing [241, 242]. PRP technology is based on the growth factors released from platelets, which could regulate multiple types of stem cells in the bulge of the HFs to induce the generation and development of new follicles [243]. The increased hair counts and total hair density, and increased epidermis thickness and of the number of HFs have been discovered after treating with PRP, almost in AGA patients [241, 244-246].

As for drug treatment, there are only two drugs, namely Minoxidil $^{\circledR}$ and Finasteride ${ }^{\circledR}$, which have been approved for the treatment of hair loss by the US Food and Drug Administration (FDA) [247]. Compared with Minoxidil $^{\circledR}$ and Finasteride ${ }^{\circledR}$, PRP presents as positive effects on AGA patients which is in absence of major side effects. So, PRP be may regarded as a safer and more effective alternative procedure to treat against alopecia [248].

The reversing the pathological mechanisms in various agents (both in PRP and SC-based therapy) are complex, which contribute to regeneration of HFs, or creating hair, or downregulation of hair loss [249]. For example, the activation of Wnt signalling in dermal papilla cells used in stimulating hair growth; MSC-derived signalling and growth factors obtained by platelets could utilized in the improvement of hair growth via regulating cellular proliferation through inducing cell growth (binding growth factors, such as PDGF, TGF- $\beta$, and VEGF), and 


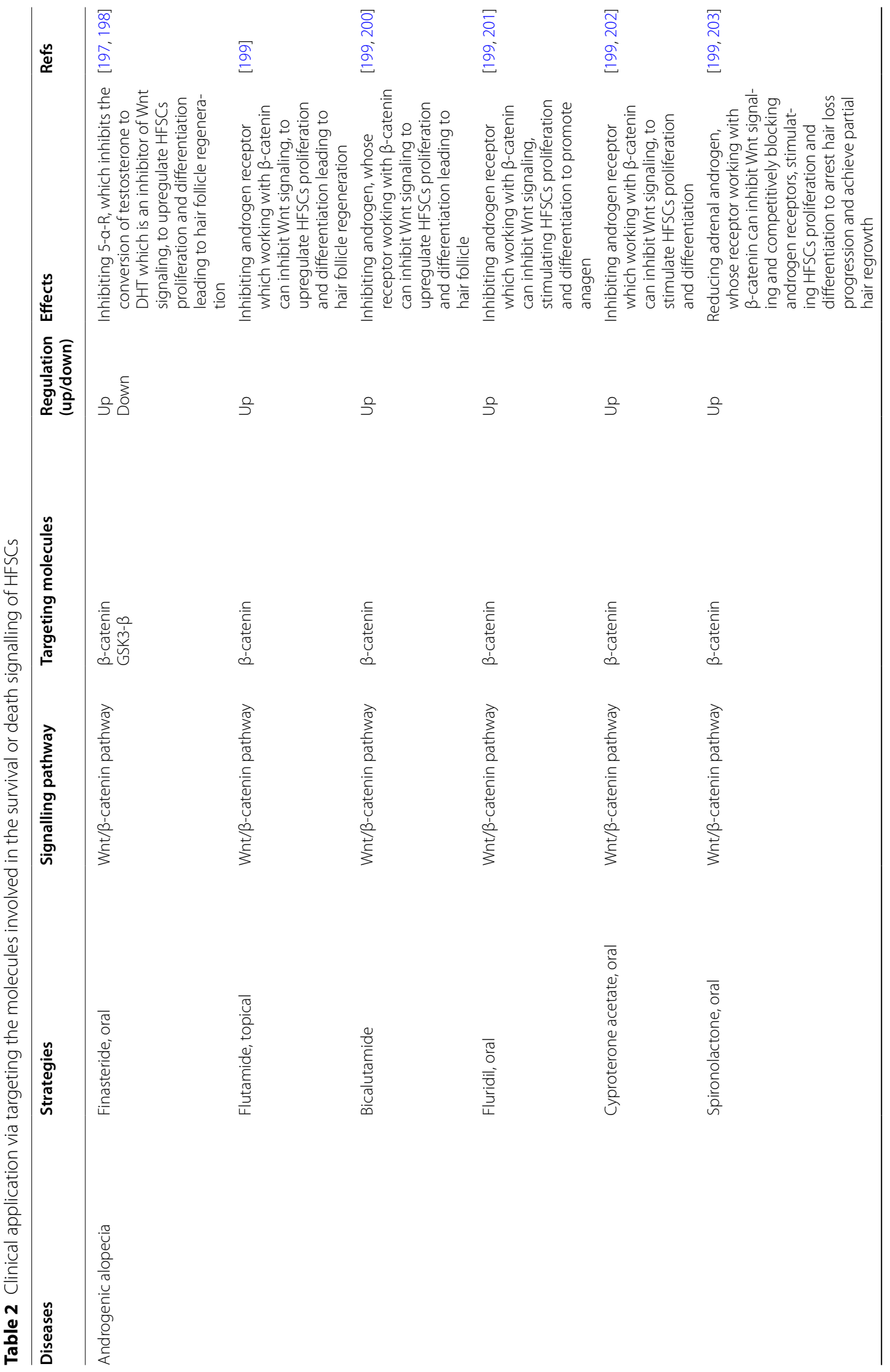




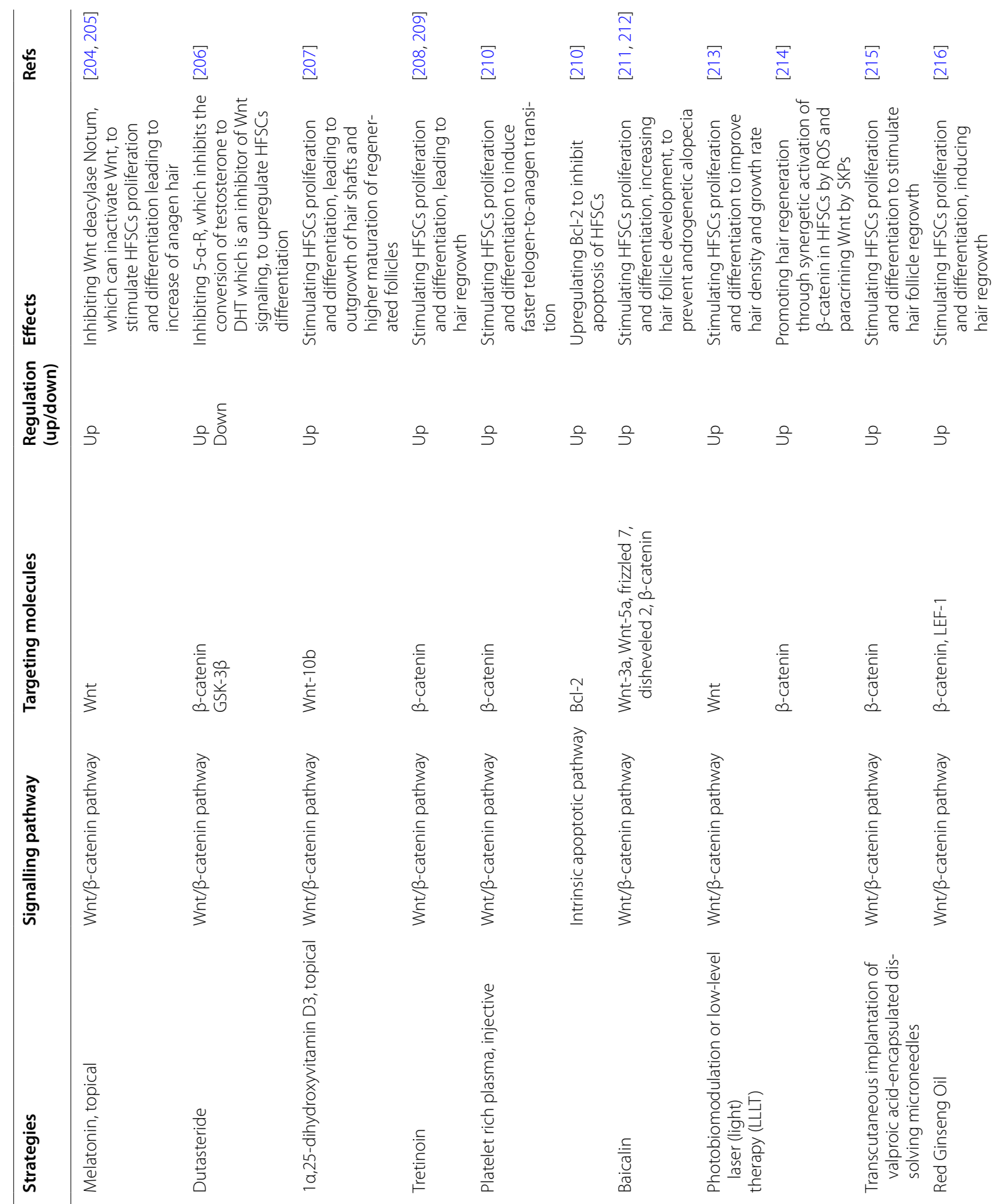




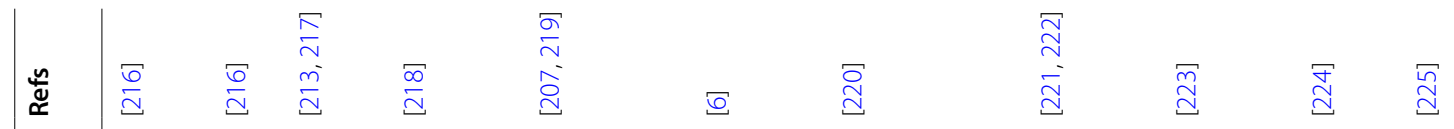

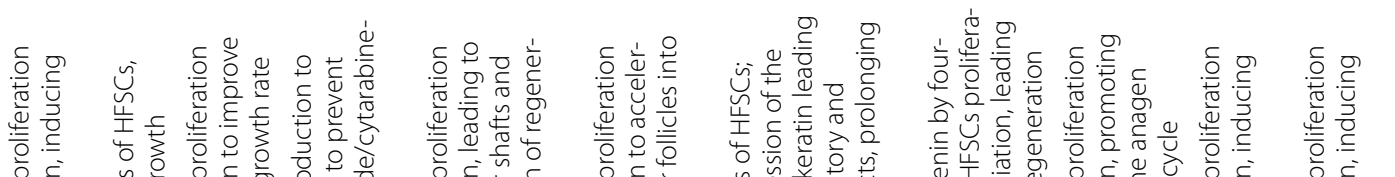
\begin{tabular}{llllll} 
& \\
\hline
\end{tabular}

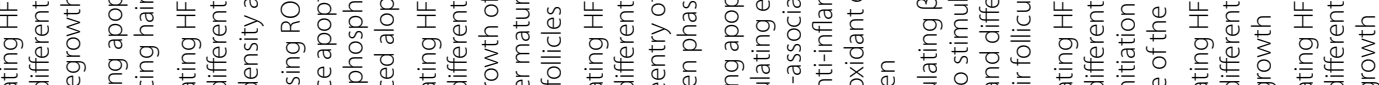

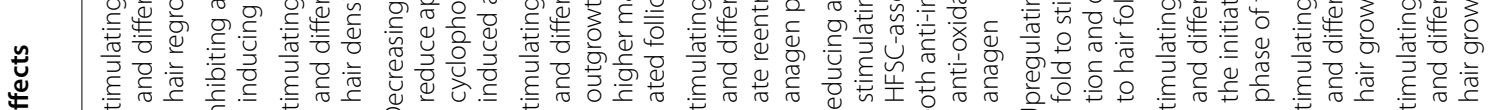

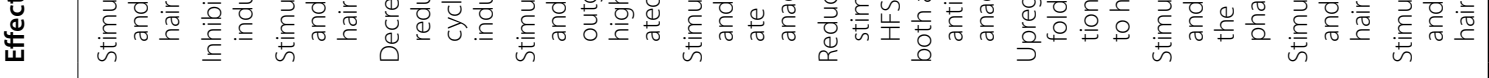

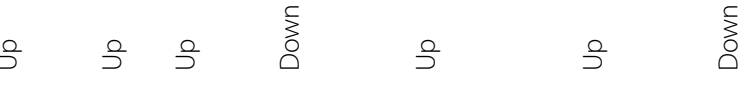

ค ค ค ค

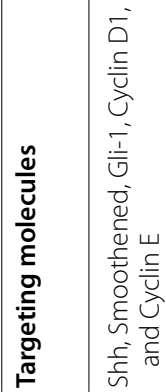

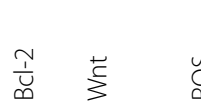

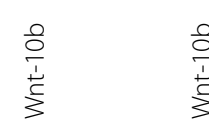

है

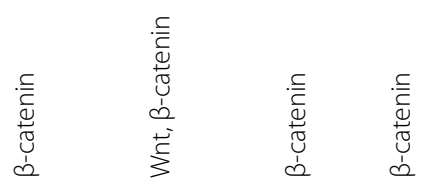

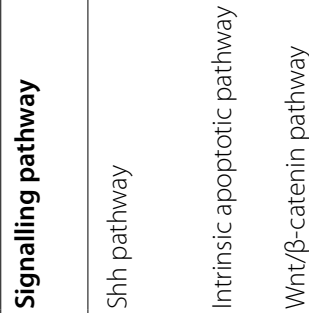

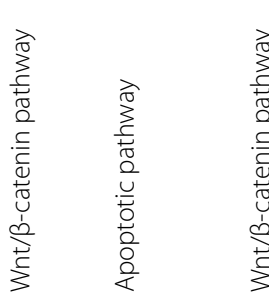

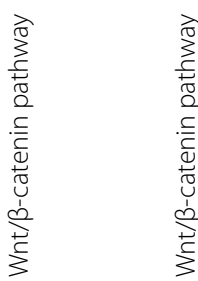

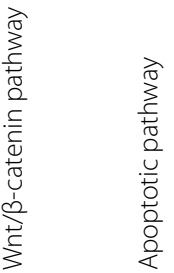

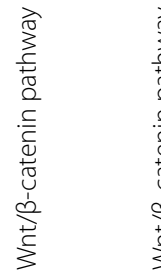

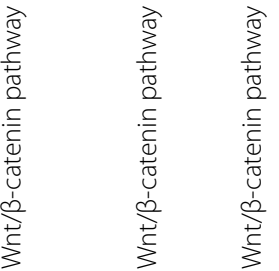
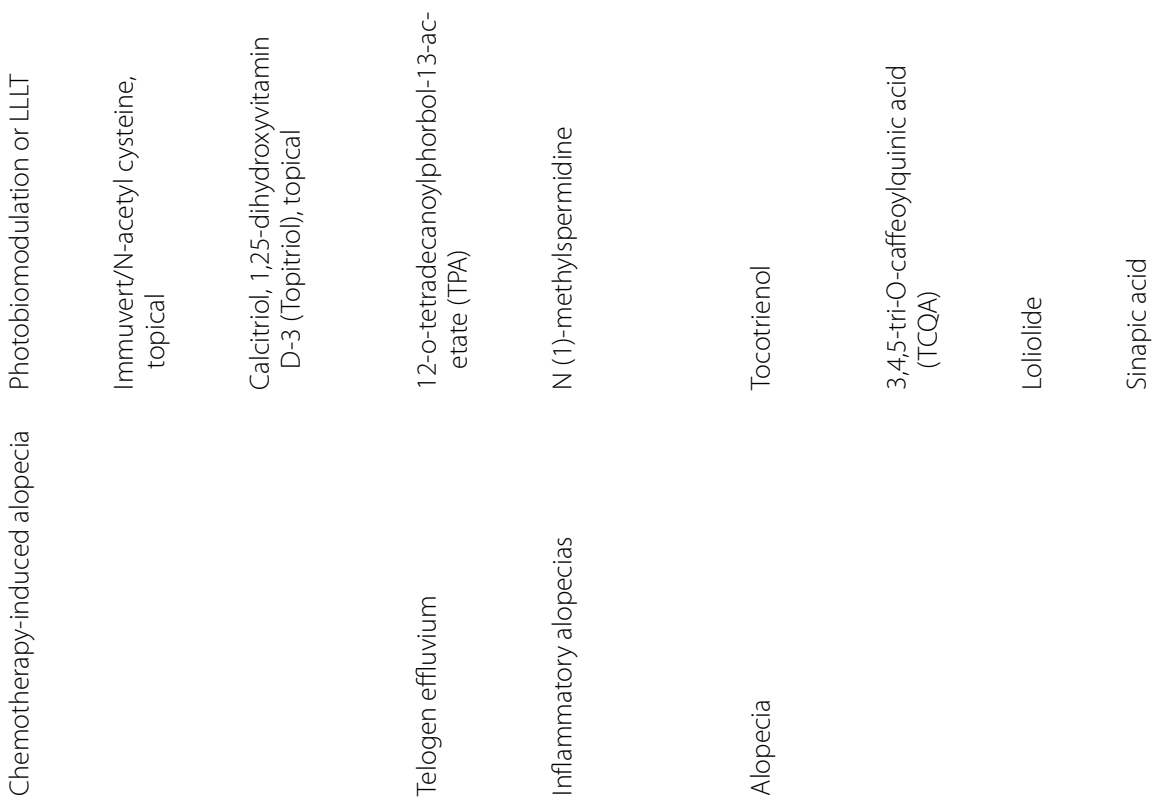

$\frac{\frac{0}{4}}{\frac{0}{\frac{0}{\alpha}}}$ 


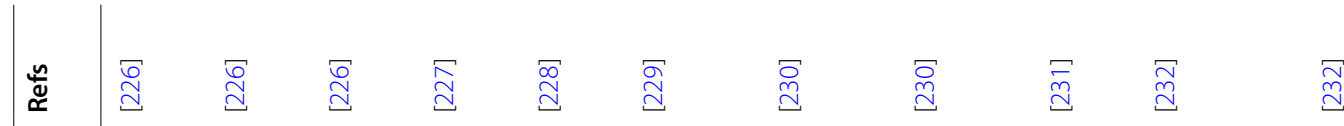

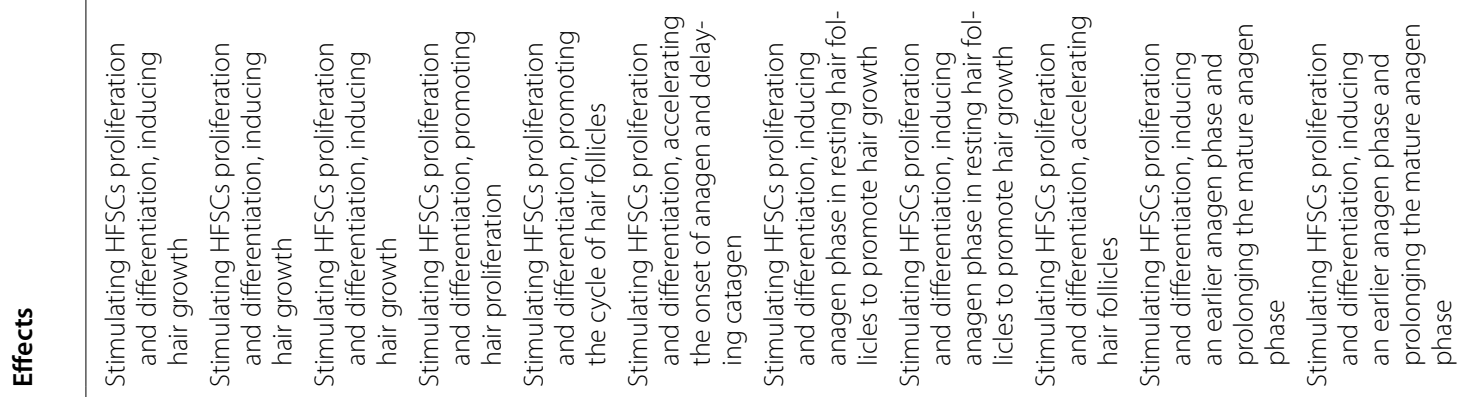

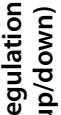

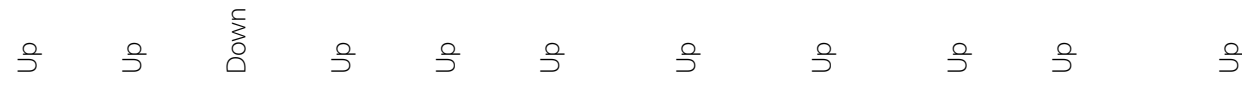

$\stackrel{2}{2}$

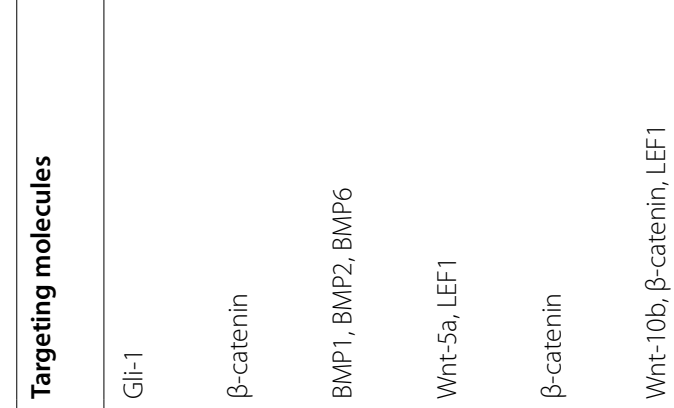
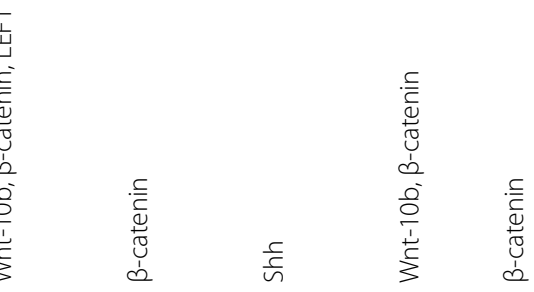

$\frac{\frac{c}{5}}{n}$

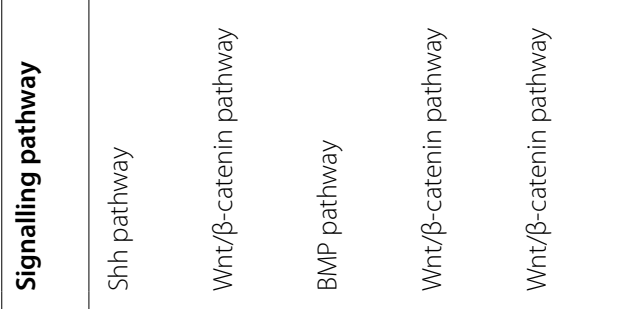
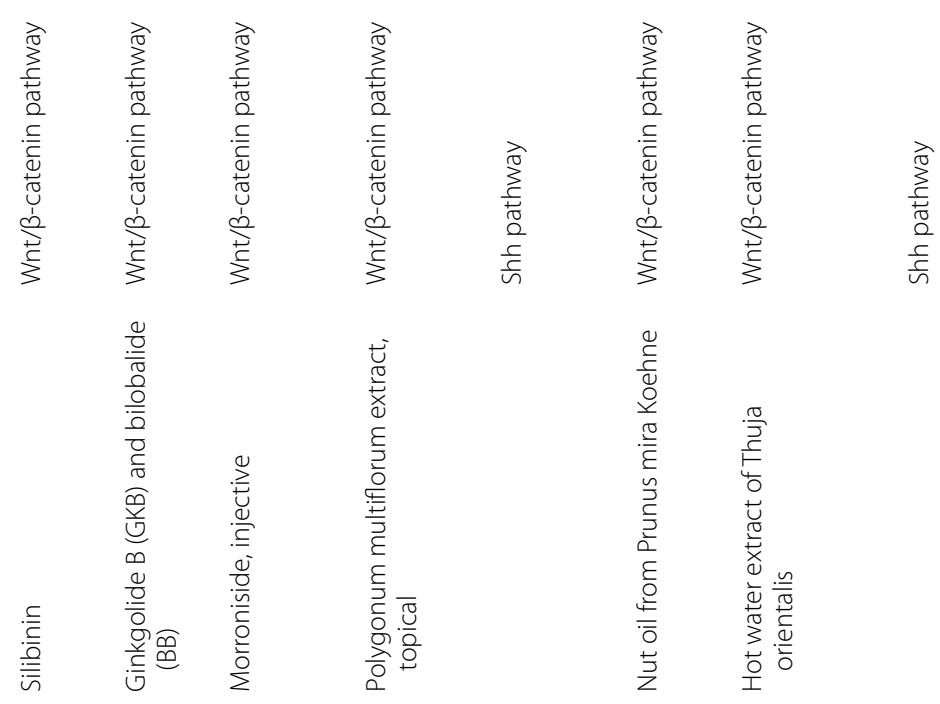

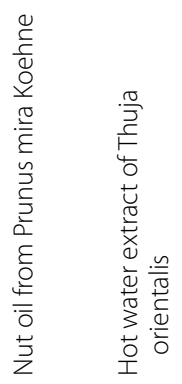




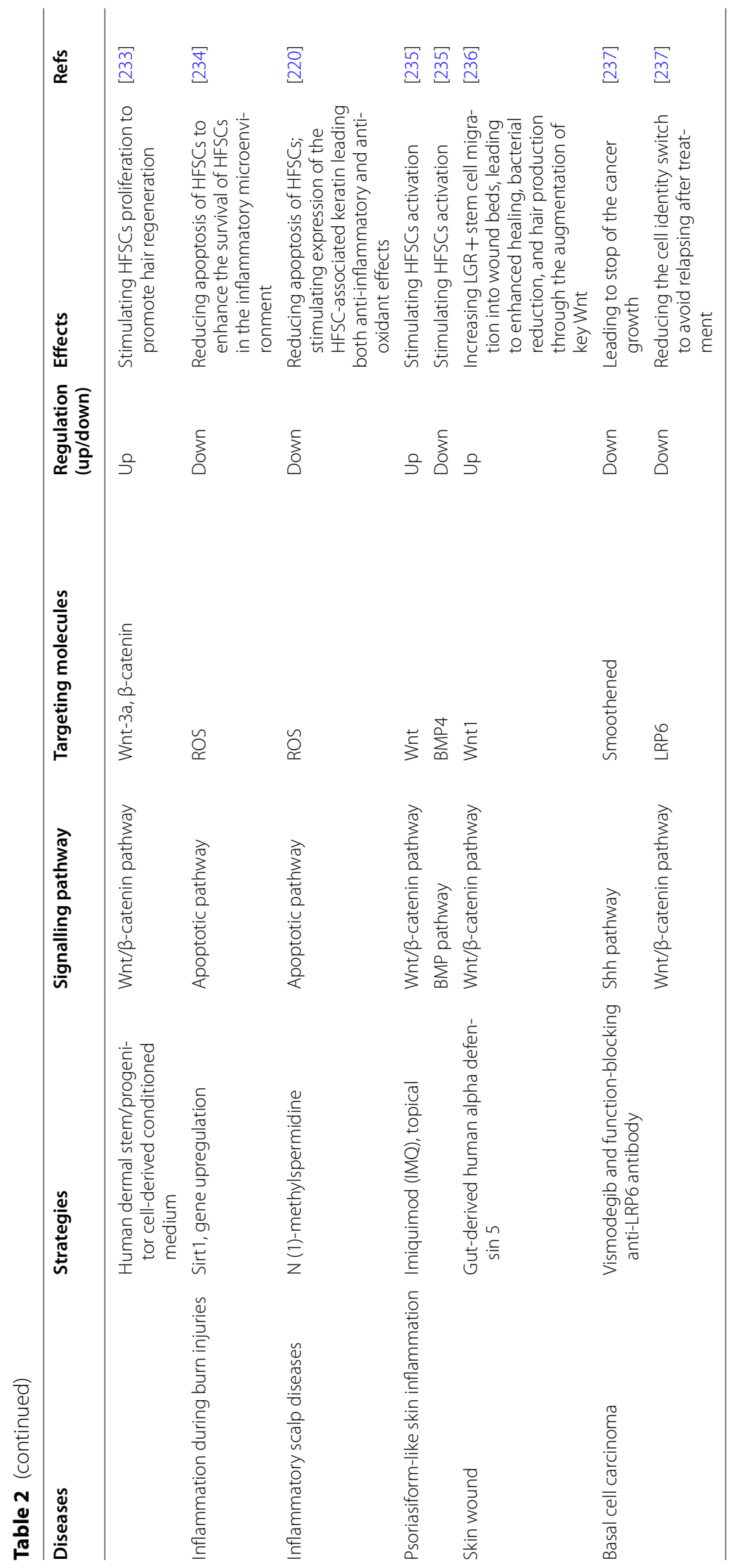


HF development (Wnt activation), and suppress apoptotsis (Bcl-2 activation and release) [67, 249].

In the epidermis, overexpression of Wnt ligand can increase the number of regenerated HFs after wounding-induced folliculogenesis, providing a window for HF neogenesis in wounded tissue, hair loss and other degenerative skin disorders through Wnt protein signalling [250, 251]. Qiu et al. reported that TPA (12-o-tetradecanoylphorbol-13-acetate, a tumour promoter) can accelerate the re-entry of HFSCs into the anagen phase through various processes, such as the induction of Akt signalling to inhibit hair regeneration-related inhibitory signalling (e.g., FGF18) and then induction of $\mathrm{Wnt} / \beta$ catenin to promote hair regeneration [6].

To prevent cell loss in HF induced by chemotherapy, two broad strategies are recommended: 1) preventing toxic drugs from reaching HFs and 2) protecting cells against death by inhibiting ROS, resisting cytotoxicity mediators and upregulating Bcl-2 expression to block apoptotic signalling [3]. Additionally, various drug candidates have largely been shown effective in improving alopecia treatments whose mechanism may relate to HFSCs; however, further research is needed, including investigations into ATP-sensitive potassium channel openers, 5-a-R inhibitors, androgen receptor antagonists, topical growth factors, a diverse selection of antioxidants and botanical extracts [3].

\section{Skin cancer}

During the development of in-depth studies between molecular pathways and cancer, precise targeted therapy has been established to target key molecules that kill tumour cells and/or inhibit tumour progression. It has been reported that multiple HFSC populations readily develop BCC-like tumours in Ptch1-deleted mice, and targeting Shh signalling pathway components, such as using smoothened inhibitors (e.g., vismodegib (Erivedge ${ }^{\circledR}$ ) and sonidegib $\left(\right.$ Odomzo $\left.^{\circledR}\right)$, can treat BCC [88, 252]. Gas-PKA has been found to play an important tumour suppressive role that limits the proliferation of HFSCs and maintains proper HF homeostasis with increased Shh signalling [253]. Cisplatin and mitomycin C DNA cross-linking agents have been utilized for the treatment of epithelial cancers to promote the apoptosis of rapidly cycling tumour cells as well as HFSCs, but some studies have discovered that chemotherapeutic DNA cross-linking agents can promote stem cell hyperplasia [254, 255]. Moreover, using DAPT (24-diamino-5-phenylthiazole, a Notch signalling blocker and $\gamma$-secretase inhibitor) can lead to promotion of HFSC proliferation and inhibition of differentiation through regulation of $\mathrm{p} 21$ and Wnt-10b [97]. $\gamma$-Secretase inhibitors have been contemplated for use as potential therapies for Notch-induced cancers. Although the multiple and complex mechanisms of resistance and side effects may challenge treatment, further understanding and continued research will provide an improved systemic treatment strategy.

\section{Skin inflammation}

SC-based therapy is a promising tool for the treatment of burn injuries, whose treatment efficacy is seriously influenced by the inflammatory microenvironment in the damaged skin. To address this challenge, Sirtuin-1 (Sirt1) has been found to be an effective target to enhance the survival of HFSCs in the inflammatory microenvironment by inhibiting mitochondrial ROS overproduction, mitochondrial cyt-c liberation, and the upregulation of pro-apoptotic proteins [256]. The Yuval group showed that $0.5 \mu \mathrm{M}$ N1-MeSpd had a strong effect on human HF cycling by prolonging the anagen phase, decreasing the apoptosis rate and stimulating the expression of HFSCassociated keratin, leading to both anti-inflammatory and anti-oxidant effects [220]. Other inflammatory-related disorders, such as psoriasis and atopic dermatitis, are also treated through these signalling pathways. For example, topical imiquimod (IMQ) application can induce psoriasiform-like skin inflammation via the reduced expression of the anagen-inhibiting factor BMP-4 and the upregulation of Wnt factors, leading to HFSC activation [235]. Multiple skin diseases are closely related to inflammation, which suggests targets for treating inflammation, such as reducing ROS levels, inhibiting the release of cyt $\mathrm{C}$ and regulating survival pathways.

\section{Skin wound healing}

For scar-forming and regenerative skin wound healing, Shh signalling may be a potential target that plays a major role in preventing wounded fibroblasts from scarring by promoting and stimulating HFSC generation [121]. For skin wound healing, bioengineering revolved around the development of new autologous-technologies has led to considerable improvements, whereas skin appendages lost during injury are not regenerated [257-259]. Autologous non-activated platelet-rich plasma (A-PRP) or activated platelet-rich plasma (AA-PRP) have been utilized in wound healing. through autologous platelets derived growth factors aiming to aid the wound healing process. These factors could support in hair activation, induce cell differentiation, proliferation and neo-angiogenesis $[259,260]$.

Recently, a combination of culture-expanded HFSCs and skin-derived precursors (SKPs) was sufficient to regenerate de novo HFs through upregulation of BMP4 [261]. Moreover, an immune-related pathway known as the macrophage-TNF-induced AKT/ $\beta$-catenin signalling 
pathway plays a crucial role in HFSCs to promote HF cycling and neogenesis after wounding, which provides a novel immune point [262]. Additionally, Wnt proteins may provide a mechanism for manipulating HF neogenesis after skin wounding. Wounding-induced folliculogenesis is abrogated after Wnt signalling is inhibited, whereas the number of regenerated HFs is upregulated through overexpression of the Wnt ligand [250]. Nonetheless, early intervention treatment in the developmental plasticity of HFSCs is necessary because SC status affecting tissue damage can be flexibly regained via early Wnt3a treatment ex vivo [263]. These targets seem to offer a good strategy for promoting skin wound healing, but the true curative effect is unsatisfactory, and the regeneration of skin through bioengineering is still a challenge that needs further study. Alternatively, conetwork signalling may be a better approach, as might be achieved through the combined leverage of the Wnt and Shh signalling pathways.

\section{Conclusions}

The balance between the survival and death of HFSCs contributes to the maintenance of a pool of HFSCs and the control of their abnormal proliferation, which is vital for tissue homeostasis and injury repair. Recent breakthroughs in novel single-cell profiling and spatial transcriptomics have led to more insights and greater understanding of the cell biology, structural and metabolic biochemistry and biological function of HFSCs from the gross and light microscopic levels to the molecular level. At the molecular level, complex and systematic signalling pathways in HFSCs have been presented for a better understanding of physiological and pathological (particularly for survival and death) processes, such as the Wnt, Shh, Notch, BMP, TGF, apoptotic, and autophagy pathways.

Notably, different signals lead to diverse characteristics during the life of HFSCs, Wnt/ $\beta$-catenin can fuel HFSC activity for HF renewal, Shh signalling can improve quiescent-HFSCs proliferation, Notch signals can stop the differentiation programmes of HFSCs, BMP signals can modulate or reinforce the quiescence of HFSCs, the apoptotic pathway can respond to damage and induce self-cleaning. However, an abnormal intensity of signalling activation may lead to a suboptimal health status, such as in Wnt-induced cancer. Practically, the signalling pathways described provide effective therapeutic targets, and various drugs have been utilized for the treatment and/or the improvement of HFSC-based therapy.

Although much has been achieved through the targeting of key molecules for therapy, such as Shh inhibitors used to treat against BCC, there are still many challenges, such as determining the mechanistic framework in HFSCs, overcoming the limited efficacy of targeted drugs, shortening the length of treatments, and minimizing possible adverse side effects. Remarkably, the multifaceted signalling network and cell-cell and multiple system interactions, as well as the complex but practical integrated network in the niche, in the life of HFSCs have captured our attention. Overall, deeper knowledge of this network is key to a better understanding of HFSCs and results-oriented therapeutic targeting.

\section{Abbreviations}

AA-PRP: Activated Platelet-rich plasma; AGA: Androgenic alopecia; A-PRP: Autologous non-activated Platelet-rich plasma; APM: Arrector pili muscle; xin2: Axis inhibition protein 2; Bax: BCl-2-associated X protein; BB: Bilobalide; BCC: Basal cell carcinoma; BCL-2: B cell lymphoma 2; bHLH: Basic helix-loop-helix; BMP: Bone morphogenetic proteins; BMPR: Bone morphogenetic protein receptor; Bu: Busulfan; Cdh: Congenital diaphragmatic hernia; Co-A: Coactivators; Co-R: Corepressor; cyt C: Cytochrome C; DAPT: 24-Diamino-5-phenylthiazole; DHT: Dihydrotestosterone; DISC: Death-inducing signalling complex; DP: Dermal papilla; Dvl: Disheveled; EGFR: Epidermal growth factor receptor; FADD: Fas-associated death domain; Fgf: Fibroblast growth factor; Flg: Filaggrin; Fox: Forkhead box; Foxp1: Forkhead box protein 1; Gli: Glioma-associated oncogene homolog; GPCR: G protein-coupled receptor; GSK-3 $\beta$ : Glycogen synthase kinase-3B; HDACs: Histone deacetylases; Hes: Hairy enhancer of the split; Hey: Hairy/enhancer-of-split related with YRPW motif; HFs: Hair follicles; HFSCs: Hair follicle stem cells; HG: Hair germ; hHFSC: Human hair follicle stem cells; IGFBP: Insulin-like growth factor-binding protein; IGFR: Insulin-like growth factor; IMQ: Topical imiquimod; IRS: Inner root sheath; Jag1: Jagged 1; K15: Keratin 15; KC: Keratinocytes; Lef: Lymphoid enhancer-binding factor; Lgr: Leucine-rich repeat-containing G protein-coupled receptor; Lhx: LIM homeobox; LLLT: Low-level laser (light) therapy; Lrp5/6: Receptors lipoprotein receptor-related protein; MAM: Mastermind; miRNAs, miRs: MicroRNAs; MOMP: Mitochondrial outer membrane permeabilization; NICD: Notch intracellular domain; OMM: Outer mitochondrial membrane; ORS: Outer root sheath; PDGF: Platelet-derived growth factor; PHLDA1: Pleckstrin homology-like domain family A member 1; PMAIP1: Phorbol-12-myristate-13-acetate-induced protein 1; PRP: Platelet-rich plasma; PTCH: Patched; Ptch1: Patched-1; PTEN: Phosphatase and tensin homologue; PUMA: P53 upregulated modulator of apoptosis; SC: Stem cell; SFRP-1: Secreted frizzled-related protein-1; Shh: Sonic hedgehog; Sirt1: Sirtuin-1; SKPs: Skin-derived precursors; Smo: Smoothened; Sox: SRYrelated high-mobility-group box; TACs: Transient amplifying cells; Tcf: T-cell factor; TCQA: 3,4,5-Tri-O-caffeoylquinic acid; TDAG51:T cell death-associated gene 51; TGF-a: Transforming growth factor-a; TGF- $\beta$ : Transforming growth factor-beta; TGM: Transglutaminase; Tmeff1: Tomoregulin-1; TNFR: Tumour necrosis factor receptor; TPA: 12-O-tetradecanoyl phorbol-13-acetate; UV: Ultraviolet; VEGF: Vascular endothelial growth factor.

\section{Acknowledgements}

We would like to thank for English language editing on the SNAS website.

\section{Authors' contributions}

XMH was the major contributor to reviewing the literature, writing the manuscript, and creating descriptive figures. ZXL was a major contributor to editing the tables and figures. DYZ and YCY assisted in the literature review. KX and $\mathrm{RHY}$ were major contributors to manuscript revision. All authors read and approved the final manuscript.

\section{Funding}

This research was supported by the National Natural Science Foundation of China (81772134, 81772136, 81971891 and 81571939), Guang Dong Basic and Applied Basic Research Foundation (2021A1515011453), Foundation of Foshan City (FSOAA-KJ218-1301-0034), and Special Fund of Foshan Summit plan (2019C002). 


\section{Availability of data and materials}

Data sharing not applicable to this article as no datasets were generated or analysed during the current study.

\section{Declarations}

\section{Ethics approval and consent to participate}

Not applicable.

\section{Consent for publication}

Not applicable.

\section{Competing interests}

The authors declare that they have no competing interests.

\begin{abstract}
Author details
'Department of Anatomy and Neurobiology, School of Basic Medical Sciences, Central South University, Morphological Sciences Building, 172 Tongzi Po Road, Changsha 410013, China. ${ }^{2}$ Department of Dermatology, Xiangya Hospital, Central South University, Changsha 410013, China. ${ }^{3}$ Department of Burn Surgery, The First People's Hospital of Foshan, \#81, Lingnan North Road, Foshan 528000, China. ${ }^{4}$ Hunan Key Laboratory of Ophthalmology, Changsha 410008, China.
\end{abstract}

Received: 25 June 2021 Accepted: 26 July 2021

Published online: 11 August 2021

\section{References}

1. Schneider MR, Schmidt-UUlrich R, Paus R. The hair follicle as a dynamic miniorgan. Curr Biol. 2009;19:R132-42. https://doi.org/10.1016/j.cub. 2008.12.005.

2. Guo H, Gao WV, Endo H, McElwee KJ. Experimental and early investigational drugs for androgenetic alopecia. Expert Opin Investig Drugs. 2017;26:917-32. https://doi.org/10.1080/13543784.2017.1353598].

3. Santos Z, Avci P, Hamblin MR. Drug discovery for alopecia: gone today, hair tomorrow. Expert Opin Drug Discov. 2015;10:269-92. https://doi. org/10.1517/17460441.2015.1009892].

4. Clevers H, Loh KM, Nusse R. Stem cell signaling. An integral program for tissue renewal and regeneration: Wnt signaling and stem cell control. Science. 2014;346:1248012. https://doi.org/10.1126/science.1248012.

5. Lei M, Guo H, Qiu W, Lai X, Yang T, Widelitz RB, et al. Modulating hair follicle size with Wnt10b/DKK1 during hair regeneration. Exp Dermatol. 2014;23:407-13. https://doi.org/10.1111/exd.12416.

6. Qiu W, Lei M, Zhou L, Bai X, Lai X, Yu Y, et al. Hair follicle stem cell proliferation, Akt and Wnt signaling activation in TPA-induced hair regeneration. Histochem Cell Biol. 2017;147:749-58. https://doi.org/10. 1007/s00418-017-1540-1.

7. Hsu YC, Li L, Fuchs E. Transit-amplifying cells orchestrate stem cell activity and tissue regeneration. Cell. 2014;157:935-49. https://doi.org/10. 1016/j.cell.2014.02.057.

8. Shwartz Y, Gonzalez-Celeiro M, Chen CL, Pasolli HA, Sheu SH, Fan SM, et al. Cell Types Promoting Goosebumps Form a Niche to Regulate Hair Follicle Stem Cells. Cell. 2020;182:578-93 e19. https://doi.org/10.1016/j. cell.2020.06.031.

9. Ali N, Zirak B, Rodriguez RS, Pauli ML, Truong HA, Lai K, et al. Regulatory $T$ cells in skin facilitate epithelial stem cell differentiation. Cell. 2017;169:1119-29 e11. https://doi.org/10.1016/j.cell.2017.05.002

10. Maryanovich M, Frenette PS. T-regulating hair follicle stem cells. Immunity. 2017:46:979-81. https://doi.org/10.1016/j.immuni.2017.06.011.

11. Oshimori N, Fuchs E. Paracrine TGF-beta signaling counterbalances BMP-mediated repression in hair follicle stem cell activation. Cell Stem Cell. 2012;10:63-75. https://doi.org/10.1016/j.stem.2011.11.005.

12. Schuler N, Timm S, Rube CE. Hair follicle stem cell faith is dependent on chromatin remodeling capacity following low-dose radiation. Stem Cells. 2018;36:574-88. https://doi.org/10.1002/stem.2768.
13. Plikus MV, Mayer JA, de la Cruz D, Baker RE, Maini PK, Maxson R, et al. Cyclic dermal BMP signalling regulates stem cell activation during hair regeneration. Nature. 2008;451:340-4. https://doi.org/10.1038/natur e06457.

14. Blanpain C, Fuchs E. Epidermal stem cells of the skin. Annu Rev Cell Dev Biol. 2006;22:339-73. https://doi.org/10.1146/annurev.cellbio.22. 010305.104357.

15. Mii S, Duong J, Tome Y, Uchugonova A, Liu F, Amoh Y, et al. The role of hair follicle nestin-expressing stem cells during whisker sensory-nerve growth in long-term 3D culture. J Cell Biochem. 2013;1 14:1674-84. https://doi.org/10.1002/jcb.24509.

16. Cotsarelis G, Sun TT, Lavker RM. Label-retaining cells reside in the bulge area of pilosebaceous unit: implications for follicular stem cells, hair cycle, and skin carcinogenesis. Cell. 1990;61:1329-37. https://doi.org/ 10.1016/0092-8674(90)90696-c.

17. Nishimura EK, Jordan SA, Oshima H, Yoshida H, Osawa M, Moriyama M, et al. Dominant role of the niche in melanocyte stem-cell fate determination. Nature. 2002;416:854-60. https://doi.org/10.1038/416854a.

18. Toma JG, Akhavan M, Fernandes KJ, Barnabe-Heider F, Sadikot A, Kaplan $\mathrm{DR}$, et al. Isolation of multipotent adult stem cells from the dermis of mammalian skin. Nat Cell Biol. 2001;3:778-84. https://doi.org/10.1038/ ncb0901-778.

19. Amoh Y, Li L, Campillo R, Kawahara K, Katsuoka K, Penman S, et al. Implanted hair follicle stem cells form Schwann cells that support repair of severed peripheral nerves. Proc Natl Acad Sci U S A. 2005;102:177348. https://doi.org/10.1073/pnas.0508440102.

20. Nagel S, Rohr F, Weber C, Kier J, Siemers F, Kruse C, et al. Multipotent nestin-positive stem cells reside in the stroma of human eccrine and apocrine sweat glands and can be propagated robustly in vitro. PLoS ONE. 2013;8:e78365. https://doi.org/10.1371/journal.pone.0078365.

21. Fuchs E. Scratching the surface of skin development. Nature. 2007:445:834-42. https://doi.org/10.1038/nature05659.

22. Hsu YC, Pasolli HA, Fuchs E. Dynamics between stem cells, niche, and progeny in the hair follicle. Cell. 2011;144:92-105. https://doi.org/10. 1016/j.cell.2010.11.049.

23. Tumbar T, Guasch G, Greco V, Blanpain C, Lowry WE, Rendl M, et al. Defining the epithelial stem cell niche in skin. Science. 2004;303:35963. https://doi.org/10.1126/science.1092436.

24. Paus R, Foitzik K. In search of the "hair cycle clock": a guided tour. Differentiation. 2004;72:489-511. https://doi.org/10.1111/j.1432-0436.2004. 07209004.x.

25. Muller-Rover S, Handjiski B, van der Veen C, Eichmuller S, Foitzik K, McKay IA, et al. A comprehensive guide for the accurate classification of murine hair follicles in distinct hair cycle stages. J Invest Dermatol. 2001;117:3-15. https://doi.org/10.1046/j.0022-202x.2001.01377.x.

26. Chen CL, Huang WY, Wang EHC, Tai KY, Lin SJ. Functional complexity of hair follicle stem cell niche and therapeutic targeting of niche dysfunction for hair regeneration. J Biomed Sci. 2020;27:43. https://doi.org/10. 1186/s12929-020-0624-8.

27. Wang $A B$, Jain $P$, Tumbar T. The hair follicle stem cell niche: the bulge and its environment. In: Turksen K, editor. Tissue-specific stem cell niche. Cham: Springer International Publishing; 2015. p. 1-26.

28. Li L, Clevers H. Coexistence of quiescent and active adult stem cells in mammals. Science. 2010;327:542-5. https://doi.org/10.1126/science. 1180794.

29. Buffoli B, Rinaldi F, Labanca M, Sorbellini E, Trink A, Guanziroli E, et al. The human hair: from anatomy to physiology. Int J Dermatol. 2014;53:33141. https://doi.org/10.1111/ijd.12362.

30. Inoue K, Aoi N, Sato T, Yamauchi Y, Suga H, Eto H, et al. Differential expression of stem-cell-associated markers in human hair follicle epithelial cells. Lab Invest. 2009;89:844-56. https://doi.org/10.1038/labin vest.2009.48

31. Lyle S, Christofidou-Solomidou M, Liu Y, Elder DE, Albelda S, Cotsarelis $\mathrm{G}$. The C8/144B monoclonal antibody recognizes cytokeratin 15 and defines the location of human hair follicle stem cells. J Cell Sci. 1998;111(Pt 21):3179-88.

32. Lyle S, Christofidou-Solomidou M, Liu Y, Elder DE, Albelda S, Cotsarelis G. Human hair follicle bulge cells are biochemically distinct and possess an epithelial stem cell phenotype. J Investig Dermatol Symp Proc. 1999;4:296-301. https://doi.org/10.1038/sj.jidsp.5640233. 
33. Liu Y, Lyle S, Yang Z, Cotsarelis G. Keratin 15 promoter targets putative epithelial stem cells in the hair follicle bulge. J Invest Dermatol. 2003;121:963-8. https://doi.org/10.1046/j.1523-1747.2003.12600.x.

34. Kloepper JE, Tiede S, Brinckmann J, Reinhardt DP, Meyer W, Faessler R, et al. Immunophenotyping of the human bulge region: the quest to define useful in situ markers for human epithelial hair follicle stem cells and their niche. Exp Dermatol. 2008;17:592-609. https://doi.org/10. 1111/j.1600-0625.2008.00720.x.

35. Al-Refu K. Stem cells and alopecia: a review of pathogenesis. $\mathrm{Br} J$ Dermatol. 2012;167:479-84. https://doi.org/10.1111/j.1365-2133.2012. 11018.x.

36. Abbas $\mathrm{O}$, Mahalingam M. Epidermal stem cells: practical perspectives and potential uses. Br J Dermatol. 2009;161:228-36. https://doi.org/10. 1111/j.1365-2133.2009.09250.x.

37. Köse O, Lalli A, Kutulola AO, Odell EW, Waseem A. Changes in the expression of stem cell markers in oral lichen planus and hyperkeratotic lesions. J Oral Sci. 2007;49:133-9. https://doi.org/10.2334/josnusd.49. 133.

38. Zhang $Y$, Xiang $M$, Wang $Y$, Yan J, Zeng $Y, Y u$ J, et al. Bulge cells of human hair follicles: segregation, cultivation and properties. Colloids Surf B Biointerfaces. 2006;47:50-6. https://doi.org/10.1016/j.colsurfb.2005.11. 017.

39. Jiang S, Zhao L, Purandare B, Hantash BM. Differential expression of stem cell markers in human follicular bulge and interfollicular epidermal compartments. Histochem Cell Biol. 2010;133:455-65. https://doi. org/10.1007/s00418-010-0684-Z

40. Michel M, Török N, Godbout MJ, Lussier M, Gaudreau P, Royal A, et al. Keratin 19 as a biochemical marker of skin stem cells in vivo and in vitro: keratin 19 expressing cells are differentially localized in function of anatomic sites, and their number varies with donor age and culture stage. J Cell Sci. 1996;109(Pt 5):1017-28 (PMID:8743949)

41. Commo S, Gaillard O, Bernard BA. The human hair follicle contains two distinct K19 positive compartments in the outer root sheath: a unifying hypothesis for stem cell reservoir? Differentiation. 2000;66:157-64. https://doi.org/10.1046/j.1432-0436.2000.660401.x.

42. Pontiggia L, Biedermann T, Meuli M, Widmer D, Böttcher-Haberzeth S, Schiestl C, et al. Markers to evaluate the quality and self-renewing potential of engineered human skin substitutes in vitro and after transplantation. J Invest Dermatol. 2009;129:480-90. https://doi.org/10. 1038/jid.2008.254

43. Ohyama M, Terunuma A, Tock CL, Radonovich MF, Pise-Masison CA, Hopping SB, et al. Characterization and isolation of stem cell-enriched human hair follicle bulge cells. J Clin Invest. 2006;116:249-60. https:// doi.org/10.1172/jci26043.

44. Sellheyer K, Krahl D. PHLDA1 (TDAG51) is a follicular stem cell marker and differentiates between morphoeic basal cell carcinoma and desmoplastic trichoepithelioma. Br J Dermatol. 2011;164:141-7. https://doi. org/10.1111/j.1365-2133.2010.10045.x.

45. Sellheyer K, Nelson P. Follicular stem cell marker PHLDA1 (TDAG51) is superior to cytokeratin-20 in differentiating between trichoepithelioma and basal cell carcinoma in small biopsy specimens. J Cutan Pathol. 2011;38:542-50. https://doi.org/10.1111/j.1600-0560.2011.01693.x.

46. Horsley V, Aliprantis AO, Polak L, Glimcher LH, Fuchs E. NFATc1 balances quiescence and proliferation of skin stem cells. Cell. 2008;132:299-310. https://doi.org/10.1016/j.cell.2007.11.047.

47. Ozawa M, Aiba S, Kurosawa M, Tagami H. Ber-EP4 antigen is a marker for a cell population related to the secondary hair germ. Exp Dermatol. 2004;13:401-5. https://doi.org/10.1111/j.0906-6705.2004.00153.x.

48. Blanco S, Bandiera R, Popis M, Hussain S, Lombard P, Aleksic J, et al. Stem cell function and stress response are controlled by protein synthesis. Nature. 2016;534:335-40. https://doi.org/10.1038/nature18282.

49. Trempus CS, Morris RJ, Ehinger M, Elmore A, Bortner CD, Ito M, et al. CD34 expression by hair follicle stem cells is required for skin tumor development in mice. Cancer Res. 2007;67:4173-81. https://doi.org/10. 1158/0008-5472.Can-06-3128.

50. Poblet E, Jiménez F, Godínez JM, Pascual-Martín A, Izeta A. The immunohistochemical expression of CD34 in human hair follicles: a comparative study with the bulge marker CK15. Clin Exp Dermatol. 2006;31:807-12. https://doi.org/10.1111/j.1365-2230.2006.02255.x.

51. Snippert HJ, Haegebarth A, Kasper M, Jaks V, van Es JH, Barker N, et al. Lgr6 marks stem cells in the hair follicle that generate all cell lineages of the skin. Science. 2010;327:1385-9. https://doi.org/10.1126/science. 1184733.

52. Joost S, Jacob T, Sun X, Annusver K, La Manno G, Sur I, et al. Single-cell transcriptomics of traced epidermal and hair follicle stem cells reveals rapid adaptations during wound healing. Cell Rep. 2018;25:585-97 e7. https://doi.org/10.1016/j.celrep.2018.09.059.

53. Tanabe K, Amoh Y, Kanoh M, Takasu H, Sakai N, Sato Y, et al. Prognostic significance of the hair follicle stem cell marker nestin in patients with malignant melanoma. Eur J Dermatol. 2010;20:283-8. https://doi.org/ 10.1684/ejd.2010.0909.

54. Nath M, Offers M, Hummel M, Seissler J. Isolation and in vitro expansion of Lgr6-positive multipotent hair follicle stem cells. Cell Tissue Res. 2011;344:435-44. https://doi.org/10.1007/s00441-011-1165-y.

55. Mii S, Amoh Y, Katsuoka K, Hoffman RM. Comparison of nestin-expressing multipotent stem cells in the tongue fungiform papilla and vibrissa hair follicle. J Cell Biochem. 2014;115:1070-6. https://doi.org/10.1002/ jcb.24696.

56. Rompolas P, Greco V. Stem cell dynamics in the hair follicle niche. Sem Cell Dev Biol. 2014;25-26:34-42. https://doi.org/10.1016/j.semcdb.2013. 12.005.

57. Yari A, Heidari F, Veijouye SJ, Nobakht M. Hair follicle stem cells promote cutaneous wound healing through the SDF-1a/CXCR4 axis: an animal model. J Wound Care. 2020;29:526-36. https://doi.org/10.12968/jowc 2020.29.9.526.

58. Aran S, Zahri S, Asadi A, Khaksar F, Abdolmaleki A. Hair follicle stem cells differentiation into bone cells on collagen scaffold. Cell Tissue Bank. 2020;21:181-8. https://doi.org/10.1007/s10561-020-09812-9.

59. Kanno H. Regenerative therapy for neuronal diseases with transplantation of somatic stem cells. World J Stem Cells. 2013;5:163-71. https:// doi.org/10.4252/wjsc.v5.i4.163.

60. Zhang $X$, Tang H, Mao S, Li B, Zhou Y, Yue H, et al. Transplanted hair follicle stem cells migrate to the penumbra and express neural markers in a rat model of cerebral ischaemia/reperfusion. Stem Cell Res Therapy. 2020;11:413. https://doi.org/10.1186/s13287-020-01927-w].

61. Babakhani A, Nobakht M, Pazoki Torodi H, Dahmardehei M, Hashemi P, Mohajer Ansari J, et al. Effects of hair follicle stem cells on partialthickness burn wound healing and tensile strength. Iran Biomed J. 2020;24:99-109. https://doi.org/10.29252/ibj.24.2.99.

62. Gur-Cohen S, Yang H, Baksh SC, Miao Y, Levorse J, Kataru RP, et al. Stem cell-driven lymphatic remodeling coordinates tissue regeneration. Science (New York, NY). 2019;366:1218-25. https://doi.org/10.1126/scien ce.aay4509.

63. Li KN, Jain P, He CH, Eun FC, Kang S, Tumbar T. Skin vasculature and hair follicle cross-talking associated with stem cell activation and tissue homeostasis. eLife 2019; 8: [PMID:31343406 DOI: https://doi.org/10. 7554/eLife.45977]

64. Yang ZY, Zhou L, Meng Q, Shi H, Li YH. An appropriate level of autophagy reduces emulsified isoflurane-induced apoptosis in fetal neural stem cells. Neural Regen Res. 2020;15:2278-85. https://doi.org/ 10.4103/1673-5374.285004.

65. Vogel S, Hoehn M, Aswendt M. In vivo bioluminescence imaging to elucidate stem cell graft differentiation. Neural Regen Res. 2020;15:61-2. https://doi.org/10.4103/1673-5374.264449.

66. Singh A, Singh A, Sand JM, Heninger E, Hafeez BB, Verma AK. Protein kinase $C$ epsilon, which is linked to ultraviolet radiation-induced development of squamous cell carcinomas, stimulates rapid turnover of adult hair follicle stem cells. J Skin Cancer. 2013;2013:452425. https:// doi.org/10.1155/2013/452425.

67. Gentile P, Garcovich S. Advances in regenerative stem cell therapy in androgenic alopecia and hair loss: Wnt pathway, growth-factor, and mesenchymal stem cell signaling impact analysis on cell growth and hair follicle development. Cells. 2019. https://doi.org/10.3390/cells 8050466.

68. Zhu M, Kong D, Tian R, Pang M, Mo M, Chen Y, et al. Platelet sonicates activate hair follicle stem cells and mediate enhanced hair follicle regeneration. J Cell Mol Med. 2020;24:1786-94. https://doi.org/10.1111/ jcmm.14873.

69. Gonzalez-Fernandez C, Gonzalez P, Rodriguez FJ. New insights into Wnt signaling alterations in amyotrophic lateral sclerosis: a potential therapeutic target? Neural Regen Res. 2020;15:1580-9. https://doi.org/ 10.4103/1673-5374.276320. 
70. Huelsken J, Vogel R, Erdmann B, Cotsarelis G, Birchmeier W. betaCatenin controls hair follicle morphogenesis and stem cell differentiation in the skin. Cell. 2001;105:533-45. https://doi.org/10.1016/s00928674(01)00336-1.

71. Gat U, DasGupta R, Degenstein L, Fuchs E. De Novo hair follicle morphogenesis and hair tumors in mice expressing a truncated betacatenin in skin. Cell. 1998;95:605-14. https://doi.org/10.1016/s00928674(00)81631-1.

72. Su Y, Wen J, Zhu J, Xie Z, Liu C, Ma C, et al. Pre-aggregation of scalp progenitor dermal and epidermal stem cells activates the WNT pathway and promotes hair follicle formation in in vitro and in vivo systems. Stem Cell Res Ther. 2019;10:403. https://doi.org/10.1186/ s13287-019-1504-6.

73. Tripurani SK, Wang Y, Fan YX, Rahimi M, Wong L, Lee MH, et al. Suppression of Wnt/beta-catenin signaling by EGF receptor is required for hair follicle development. Mol Biol Cell. 2018;29:2784-99. https://doi.org/10. 1091/mbc.E18-08-0488.

74. Driskell RR, Lichtenberger BM, Hoste E, Kretzschmar K, Simons BD, Charalambous M, et al. Distinct fibroblast lineages determine dermal architecture in skin development and repair. Nature. 2013;504:277-81. https://doi.org/10.1038/nature12783.

75. Wu P, Zhang Y, Xing Y, Xu W, Guo H, Deng F, et al. Correction to: the balance of Bmp6 and Wnt10b regulates the telogen-anagen transition of hair follicles. Cell Commun Signal. 2020;18:4. https://doi.org/10.1186/ s12964-020-0508-2.

76. Hawkshaw NJ, Hardman JA, Alam M, Jimenez F, Paus R. Deciphering the molecular morphology of the human hair cycle: Wnt signalling during the telogen-anagen transformation. Br J Dermatol. 2020;182:1184-93. https://doi.org/10.1111/bjd.18356.

77. Lowry WE, Blanpain C, Nowak JA, Guasch G, Lewis L, Fuchs E. Defining the impact of beta-catenin/Tcf transactivation on epithelial stem cells. Genes Dev. 2005;19:1596-611. https://doi.org/10.1101/gad.1324905.

78. Yan H, Gao Y, Ding Q, Liu J, Li Y, Jin M, et al. Exosomal micro RNAs derived from dermal papilla cells mediate hair follicle stem cell proliferation and differentiation. Int J Biol Sci. 2019;15:1368-82. https://doi. org/10.7150/ijbs.33233.

79. Alonso L, Fuchs E. Stem cells in the skin: waste not, Wnt not. Genes Dev. 2003;17:1189-200. https://doi.org/10.1101/gad.1086903.

80. Veltri A, Lang C, Lien WH. Concise review: Wnt signaling pathways in skin development and epidermal stem cells. Stem Cells. 2018;36:22-35. https://doi.org/10.1002/stem.2723.

81. Kato S, Weng QY, Insco ML, Chen KY, Muralidhar S, Pozniak J, et al. Gainof-function genetic alterations of G9a drive oncogenesis. Cancer Discov. 2020;10:980-97. https://doi.org/10.1158/2159-8290.CD-19-0532.

82. Fuccillo M, Joyner AL, Fishell G. Morphogen to mitogen: the multiple roles of hedgehog signalling in vertebrate neural development. Nat Rev Neurosci. 2006;7:772-83. https://doi.org/10.1038/nrn1990.

83. Rishikaysh P, Dev K, Diaz D, Qureshi WM, Filip S, Mokry J. Signaling involved in hair follicle morphogenesis and development. Int J Mol Sci. 2014;15:1647-70. https://doi.org/10.3390/ijms15011647.

84. Casali A, Struhl G. Reading the Hedgehog morphogen gradient by measuring the ratio of bound to unbound Patched protein. Nature. 2004:431:76-80. https://doi.org/10.1038/nature02835.

85. Carballo GB, Honorato JR, de Lopes GPF, Spohr T. A highlight on Sonic hedgehog pathway. Cell Commun Signal. 2018;16:11. https://doi.org/ 10.1186/s12964-018-0220-7.

86. Jeng KS, Chang CF, Lin SS. Sonic Hedgehog signaling in organogenesis, tumors, and tumor microenvironments. Int J Mol Sci. 2020. https://doi. org/10.3390/ijms21030758.

87. Pham A, Therond P, Alves G, Tournier FB, Busson D, Lamour-Isnard $C$, et al. The suppressor of fused gene encodes a novel PEST protein involved in Drosophila segment polarity establishment. Genetics. 1995;140:587-98.

88. Peterson SC, Eberl M, Vagnozzi AN, Belkadi A, Veniaminova NA, Verhaegen $M E$, et al. Basal cell carcinoma preferentially arises from stem cells within hair follicle and mechanosensory niches. Cell Stem Cell. 2015;16:400-12. https://doi.org/10.1016/j.stem.2015.02.006.

89. Bonilla X, Parmentier L, King B, Bezrukov F, Kaya G, Zoete V, et al. Genomic analysis identifies new drivers and progression pathways in skin basal cell carcinoma. Nat Genet. 2016;48:398-406. https://doi.org/ 10.1038/ng.3525.
90. Kasper M, Jaks V, Are A, Bergstrom A, Schwager A, Svard J, et al. Wounding enhances epidermal tumorigenesis by recruiting hair follicle keratinocytes. Proc Natl Acad Sci U S A. 2011;108:4099-104. https://doi. org/10.1073/pnas.1014489108.

91. Wang GY, Wang J, Mancianti ML, Epstein EH Jr. Basal cell carcinomas arise from hair follicle stem cells in Ptch1(+/-) mice. Cancer Cell. 2011;19:114-24. https://doi.org/10.1016/j.ccr.2010.11.007.

92. Sanchez-Danes A, Larsimont JC, Liagre M, Munoz-Couselo E, Lapouge $G$, Brisebarre A, et al. A slow-cycling LGR5 tumour population mediates basal cell carcinoma relapse after therapy. Nature. 2018;562:434-8. https://doi.org/10.1038/s41586-018-0603-3.

93. Ouspenskaia T, Matos I, Mertz AF, Fiore VF, Fuchs E. WNT-SHH antagonism specifies and expands stem cells prior to niche formation. Cell. 2016;164:156-69. https://doi.org/10.1016/j.cell.2015.11.058.

94. Kopan R, Weintraub H. Mouse notch: expression in hair follicles correlates with cell fate determination. J Cell Biol. 1993;121:631-41. https:// doi.org/10.1083/jcb.121.3.631.

95. Pan Y, Lin MH, Tian X, Cheng HT, Gridley T, Shen J, et al. gammasecretase functions through Notch signaling to maintain skin appendages but is not required for their patterning or initial morphogenesis. Dev Cell. 2004;7:731-43. https://doi.org/10.1016/j.devcel.2004.09.014.

96. Vauclair S, Nicolas M, Barrandon Y, Radtke F. Notch1 is essential for postnatal hair follicle development and homeostasis. Dev Biol. 2005;284:184-93. https://doi.org/10.1016/j.ydbio.2005.05.018.

97. Jiang J, Miao Y, Xiao S, Zhang Z, Hu Z. DAPT in the control of human hair follicle stem cell proliferation and differentiation. Postepy Dermatol Alergol. 2014;31:201-6. https://doi.org/10.5114/pdia.2014.44002.

98. Yamamoto N, Tanigaki K, Han H, Hiai H, Honjo T. Notch/RBP-J signaling regulates epidermis/hair fate determination of hair follicular stem cells. Curr Biol. 2003;13:333-8. https://doi.org/10.1016/s0960-9822(03) $00081-2$.

99. Lu Z, Xie Y, Huang H, Jiang K, Zhou B, Wang F, et al. Hair follicle stem cells regulate retinoid metabolism to maintain the self-renewal niche for melanocyte stem cells. Elife. 2020. https://doi.org/10.7554/eLife. 52712.

100. Adam RC, Yang H, Ge Y, Lien WH, Wang P, Zhao Y, et al. Temporal layering of signaling effectors drives chromatin remodeling during hair follicle stem cell lineage progression. Cell Stem Cell. 2018;22:398-413 e7. https://doi.org/10.1016/j.stem.2017.12.004.

101. Genander M, Cook PJ, Ramskold D, Keyes BE, Mertz AF, Sandberg R, et al. BMP signaling and its PSMAD1/5 target genes differentially regulate hair follicle stem cell lineages. Cell Stem Cell. 2014;15:619-33. https:// doi.org/10.1016/j.stem.2014.09.009.

102. Infarinato NR, Stewart KS, Yang Y, Gomez NC, Pasolli HA, Hidalgo L, et al. BMP signaling: at the gate between activated melanocyte stem cells and differentiation. Genes Dev. 2020;34:1713-34. https://doi.org/10. 1101/gad.340281.120

103. Andl T, Ahn K, Kairo A, Chu EY, Wine-Lee L, Reddy ST, et al. Epithelial Bmpr1a regulates differentiation and proliferation in postnatal hair follicles and is essential for tooth development. Development. 2004;131:2257-68. https://doi.org/10.1242/dev.01125.

104. Ge M, Liu C, Li L, Lan M, Yu Y, Gu L, et al. miR-29a/b1 inhibits hair follicle stem cell lineage progression by spatiotemporally suppressing WNT and BMP signaling. Cell Rep. 2019;29:2489-504 e4. https://doi.org/10. 1016/j.celrep.2019.10.062

105. Kandyba E, Leung Y, Chen YB, Widelitz R, Chuong CM, Kobielak K. Competitive balance of intrabulge BMP/Wnt signaling reveals a robust gene network ruling stem cell homeostasis and cyclic activation. Proc Natl Acad Sci U S A. 2013;1 10:1351-6. https://doi.org/10.1073/pnas.11213 12110.

106. Chung MI, Bujnis M, Barkauskas CE, Kobayashi Y, Hogan BLM. Nichemediated BMP/SMAD signaling regulates lung alveolar stem cell proliferation and differentiation. Development. 2018. https://doi.org/10. 1242/dev.163014.

107. Diaz-Moreno M, Armenteros T, Gradari S, Hortiguela R, Garcia-Corzo L, Fontan-Lozano A, et al. Noggin rescues age-related stem cell loss in the brain of senescent mice with neurodegenerative pathology. Proc Natl Acad Sci U S A. 2018;115:11625-30. https://doi.org/10.1073/pnas.18132 05115.

108. Wu X, Shen QT, Oristian DS, Lu CP, Zheng Q, Wang HW, et al. Skin stem cells orchestrate directional migration by regulating microtubule-ACF7 
connections through GSK3beta. Cell. 2011;144:341-52. https://doi.org/ 10.1016/j.cell.2010.12.033.

109. Fatima M, Srivastav S, Ahmad MH, Mondal AC. Effects of chronic unpredictable mild stress induced prenatal stress on neurodevelopment of neonates: role of GSK-3beta. Sci Rep. 2019;9:1305. https://doi.org/10. 1038/s41598-018-38085-2.

110. Shimizu H, Morgan BA. Wnt signaling through the beta-catenin pathway is sufficient to maintain, but not restore, anagen-phase characteristics of dermal papilla cells. J Invest Dermatol. 2004;122:239-45. https:// doi.org/10.1046/j.0022-202X.2004.22224.x.

111. He J, Sheng T, Stelter AA, Li C, Zhang X, Sinha M, et al. Suppressing Wnt signaling by the hedgehog pathway through sFRP-1. J Biol Chem. 2006;281:35598-602. https://doi.org/10.1074/jbc.C600200200.

112. Woo WM, Zhen HH, Oro AE. Shh maintains dermal papilla identity and hair morphogenesis via a Noggin-Shh regulatory loop. Genes Dev. 2012;26:1235-46. https://doi.org/10.1101/gad.187401.112.

113. Hwang J, Mehrani T, Millar SE, Morasso MI. Dlx3 is a crucial regulator of hair follicle differentiation and cycling. Development. 2008;135:314959. https://doi.org/10.1242/dev.022202.

114. Kobielak K, Pasolli HA, Alonso L, Polak L, Fuchs E. Defining BMP functions in the hair follicle by conditional ablation of BMP receptor IA. J Cell Biol. 2003;163:609-23. https://doi.org/10.1083/jcb.200309042.

115. Lee GT, Hong JH, Kwak C, Woo J, Liu V, Lee C, et al. Effect of dominant negative transforming growth factor-beta receptor type II on cytotoxic activity of RAW 264.7, a murine macrophage cell line. Cancer Res. 2007;67:6717-24. https://doi.org/10.1158/0008-5472.CAN-06-4263.

116. Yuan YP, Huang K, Xu YM, Chen XC, Li HH, Cai BZ, et al. Canonical and non-canonical Wnt signaling control the regeneration of amputated rodent vibrissae follicles. J Mol Histol. 2016;47:1-8. https://doi.org/10. 1007/s10735-015-9648-X.

117. Si Y, Bai J, Wu J, Li Q, Mo Y, Fang R, et al. LncRNA PIncRNA-1 regulates proliferation and differentiation of hair follicle stem cells through TGF- $\beta 1$-mediated Wnt/ $\beta$-catenin signal pathway. Mol Med Rep. 2018;17:1191-7. https://doi.org/10.3892/mmr.2017.7944.

118. Flores A, Schell J, Krall AS, Jelinek D, Miranda M, Grigorian M, et al. Lactate dehydrogenase activity drives hair follicle stem cell activation. Nat Cell Biol. 2017;19:1017-26. https://doi.org/10.1038/ncb3575.

119. Rajendran RL, Gangadaran P, Seo CH, Kwack MH, Oh JM, Lee HW, et al. Macrophage-derived extracellular vesicle promotes hair growth. Cells. 2020. https://doi.org/10.3390/cells9040856.

120. Nguyen H, Merrill BJ, Polak L, Nikolova M, Rendl M, Shaver TM, et al. Tcf3 and Tcf4 are essential for long-term homeostasis of skin epithelia. Nat Genet. 2009;41:1068-75. https://doi.org/10.1038/ng.431.

121. Lim CH, Sun Q, Ratti K, Lee SH, Zheng Y, Takeo M, et al. Hedgehog stimulates hair follicle neogenesis by creating inductive dermis during murine skin wound healing. Nat Commun. 2018;9:4903. https://doi.org/ 10.1038/s41467-018-07142-9.

122. Nowak JA, Polak L, Pasolli HA, Fuchs E. Hair follicle stem cells are specified and function in early skin morphogenesis. Cell Stem Cell. 2008;3:33-43. https://doi.org/10.1016/j.stem.2008.05.009.

123. Nguyen MB, Cohen I, Kumar V, Xu Z, Bar C, Dauber-Decker KL, et al. FGF signalling controls the specification of hair placode-derived SOX9 positive progenitors to Merkel cells. Nat Commun. 2018;9:2333. https://doi. org/10.1038/s41467-018-04399-y.

124. Suen WJ, Li ST, Yang LT. Hes1 regulates anagen initiation and hair follicle regeneration through modulation of hedgehog signaling. Stem Cells (Dayton, Ohio). 2020;38:301-14. https://doi.org/10.1002/stem.3117.

125. Luiken S, Fraas A, Bieg M, Sugiyanto R, Goeppert B, Singer S, et al. NOTCH target gene HES5 mediates oncogenic and tumor suppressive functions in hepatocarcinogenesis. Oncogene. 2020;39:3128-44. https://doi.org/10.1038/s41388-020-1198-3.

126. Cai B, Zheng Y, Yan J, Wang J, Liu X, Yin G. BMP2-mediated PTEN enhancement promotes differentiation of hair follicle stem cells by inducing autophagy. Exp Cell Res. 2019;385:111647. https://doi.org/10. 1016/j.yexcr.2019.111647.

127. Chen H, Wang X, Chen Y, Han J, Kong D, Zhu M, et al. Pten loss in Lgr5(+) hair follicle stem cells promotes SCC development. Theranostics. 2019;9:8321-31. https://doi.org/10.7150/thno.35467.

128. Genander M, Cook PJ, Ramsköld D, Keyes BE, Mertz AF, Sandberg R, et al. BMP signaling and its pSMAD1/5 target genes differentially regulate hair follicle stem cell lineages. Cell Stem Cell. 2014;15:619-33. https:// doi.org/10.1016/j.stem.2014.09.009.

129. Kandyba E, Kobielak K. Wnt7b is an important intrinsic regulator of hair follicle stem cell homeostasis and hair follicle cycling. Stem Cells (Dayton, Ohio). 2014;32:886-901. https://doi.org/10.1002/stem.1599.

130. Oshimori N, Fuchs E. Paracrine TGF- $\beta$ signaling counterbalances BMPmediated repression in hair follicle stem cell activation. Cell Stem Cell. 2012;10:63-75. https://doi.org/10.1016/j.stem.2011.11.005.

131. Franzke CW, Cobzaru C, Triantafyllopoulou A, Löffek S, Horiuchi K, Threadgill DW, et al. Epidermal ADAM17 maintains the skin barrier by regulating EGFR ligand-dependent terminal keratinocyte differentiation. J Exp Med. 2012;209:1105-19. https://doi.org/10.1084/jem.20112 258.

132. Khurana P, Kolundzic N, Rogar M, Hobbs C, Wong X, Common JEA, et al. Stem Cell Research Lab Resource: Stem Cell Linelnduced pluripotent stem cell (iPSC) line MLi-003A derived from an individual with the maximum number of filaggrin (FLG) tandem repeats. Stem Cell Res. 2020:45:101827. https://doi.org/10.1016/.scr.2020.101827.

133. Tripurani SK, Wang Y, Fan YX, Rahimi M, Wong L, Lee MH, et al. Suppression of $\mathrm{Wnt} / \beta$-catenin signaling by EGF receptor is required for hair follicle development. Mol Biol Cell. 2018;29:2784-99. https://doi.org/10. 1091/mbc.E18-08-0488.

134. Segrelles C, García-Escudero R, Garín Ml, Aranda JF, Hernández P, Ariza JM, et al. Akt signaling leads to stem cell activation and promotes tumor development in epidermis. Stem Cells (Dayton, Ohio). 2014;32:1917-28. https://doi.org/10.1002/stem.1669.

135. Castela M, Linay F, Roy E, Moguelet $\mathrm{P}, \mathrm{Xu}$ J, Holzenberger M, et al. Igf1r signalling acts on the anagen-to-catagen transition in the hair cycle. Exp Dermatol. 2017;26:785-91. https://doi.org/10.1111/exd.13287.

136. Lay K, Kume T, Fuchs E. FOXC1 maintains the hair follicle stem cell niche and governs stem cell quiescence to preserve long-term tissue-regenerating potential. Proc Natl Acad Sci USA. 2016;113:E1506-15. https:// doi.org/10.1073/pnas.1601569113.

137. Shirokova V, Biggs LC, Jussila M, Ohyama T, Groves AK, Mikkola ML. Foxi3 deficiency compromises hair follicle stem cell specification and activation. Stem Cells (Dayton, Ohio). 2016;34:1896-908. https://doi.org/10. 1002/stem.2363.

138. Mardaryev AN, Meier N, Poterlowicz K, Sharov AA, Sharova TY, Ahmed $\mathrm{Ml}$, et al. Lh×2 differentially regulates Sox9, Tcf4 and Lgr5 in hair follicle stem cells to promote epidermal regeneration after injury. Development (Cambridge, England). 2011;138:4843-52. https://doi.org/10. 1242/dev.070284.

139. Rhee H, Polak L, Fuchs E. Lhx2 maintains stem cell character in hair follicles. Science (New York, NY). 2006;312:1946-9. https://doi.org/10. 1126/science.1128004.

140. Hu XM, Li ZX, Lin RH, Shan JQ, Yu QW, Wang RX, et al. Guidelines for regulated cell death assays: a systematic summary, a categorical comparison, a prospective. Front Cell Dev Biol. 2021;9:634. https://doi.org/ 10.3389/fcell.2021.634690.

141. Lindner G, Botchkarev VA, Botchkareva NV, Ling G, van der Veen C, Paus R. Analysis of apoptosis during hair follicle regression (catagen). Am J Pathol. 1997;151:1601-17.

142. Stenn KS, Paus R. Controls of hair follicle cycling. Physiol Rev. 2001;81:449-94. https://doi.org/10.1152/physrev.2001.81.1.449.

143. Paus R, Haslam IS, Sharov AA, Botchkarev VA. Pathobiology of chemotherapy-induced hair loss. Lancet Oncol. 2013;14:e50-9. https://doi.org/ 10.1016/S1470-2045(12)70553-3.

144. Mesa KR, Rompolas P, Zito G, Myung P, Sun TY, Brown S, et al. Nicheinduced cell death and epithelial phagocytosis regulate hair follicle stem cell pool. Nature. 2015;522:94-7. https://doi.org/10.1038/natur e14306.

145. Driskell I, Oeztuerk-Winder F, Humphreys P, Frye M. Genetically induced cell death in bulge stem cells reveals their redundancy for hair and epidermal regeneration. Stem Cells. 2015;33:988-98. https://doi.org/10. 1002/stem.1910.

146. Langan EA, Philpott MP, Kloepper JE, Paus R. Human hair follicle organ culture: theory, application and perspectives. Exp Dermatol. 2015;24:903-11. https://doi.org/10.1111/exd.12836.

147. Li ST, Suen WJ, Kao CH, Yang MK, Yang LT. Gasdermin A3-mediated cell death causes niche collapse and precocious activation of hair follicle 
stem cells. J Invest Dermatol. 2020;140:2117-28. https://doi.org/10. 1016/j.jid.2020.02.033.

148. Wu X, Hu X, Zhang Q, Liu F, Xiong K. Regulatory role of chinese herbal medicine in regulated neuronal death. CNS Neurol Disord Drug Targets. 2020. https://doi.org/10.2174/1871527319666200730165011.

149. Matthews GM, Newbold A, Johnstone RW. Intrinsic and extrinsic apoptotic pathway signaling as determinants of histone deacetylase inhibitor antitumor activity. Adv Cancer Res. 2012;116:165-97. https:// doi.org/10.1016/B978-0-12-394387-3.00005-7.

150. Wang H, Cai S, Ernstberger A, Bailey BJ, Wang MZ, Cai W, et al. Temozolomide-mediated DNA methylation in human myeloid precursor cells: differential involvement of intrinsic and extrinsic apoptotic pathways. Clin Cancer Res. 2013;19:2699-709. https://doi.org/10.1158/1078-0432. CCR-12-2671.

151. Bock FJ, Tait SWG. Mitochondria as multifaceted regulators of cell death. Nat Rev Mol Cell Biol. 2020;21:85-100. https://doi.org/10.1038/ s41580-019-0173-8.

152. Olie RA, Hafner C, Kuttel R, Sigrist B, Willers J, Dummer R, et al. BCl-2 and bcl-XL antisense oligonucleotides induce apoptosis in melanoma cells of different clinical stages. J Invest Dermatol. 2002;118:505-12. https:// doi.org/10.1046/j.0022-202x.2001.01677.x].

153. Chen J, Graham SH, Nakayama M, Zhu RL, Jin K, Stetler RA, et al. Apoptosis repressor genes $\mathrm{BCl}-2$ and $\mathrm{BCl}-\mathrm{x}$-long are expressed in the rat brain following global ischemia. J Cereb Blood Flow Metab. 1997;17:2-10. https://doi.org/10.1097/00004647-199701000-00002].

154. Adams JM, Cory S. The BCl-2 protein family: arbiters of cell survival. Science. 1998;281:1322-6. https://doi.org/10.1126/science.281.5381.1322.

155. Boise LH, Gottschalk AR, Quintans J, Thompson CB. BCl-2 and BCl2-related proteins in apoptosis regulation. Curr Top Microbiol Immunol. 1995;200:107-21. https://doi.org/10.1007/978-3-642-79437-7_8.

156. Liu JC, Lerou PH, Lahav G. Stem cells: balancing resistance and sensitivity to DNA damage. Trends Cell Biol. 2014;24:268-74. https://doi.org/10. 1016/j.tcb.2014.03.002.

157. Wang $X$, Simpson ER, Brown KA. p53: protection against tumor growth beyond effects on cell cycle and apoptosis. Cancer Res. 2015;75:5001-7. https://doi.org/10.1158/0008-5472.CAN-15-0563.

158. Gottlieb TM, Oren M. p53 and apoptosis. Semin Cancer Biol. 1998:8:359-68. https://doi.org/10.1006/scbi.1998.0098.

159. Kim JY, Ohn J, Yoon JS, Kang BM, Park M, Kim S, et al. Priming mobilization of hair follicle stem cells triggers permanent loss of regeneration after alkylating chemotherapy. Nat Commun. 2019;10:3694. https://doi. org/10.1038/s41467-019-11665-0.

160. Sotiropoulou PA, Candi A, Mascre G, De Clercq S, Youssef KK, Lapouge $\mathrm{G}$, et al. BCl-2 and accelerated DNA repair mediates resistance of hair follicle bulge stem cells to DNA-damage-induced cell death. Nat Cell Biol. 2010:12:572-82. https://doi.org/10.1038/ncb2059.

161. Palamaras I, Misciali C, Vincenzi C, Robles WS, Tosti A. Permanent chemotherapy-induced alopecia: a review. J Am Acad Dermatol. 2011;64:604-6. https://doi.org/10.1016/j.jaad.2010.03.020.

162. Choi M, Kim MS, Park SY, Park GH, Jo SJ, Cho KH, et al. Clinical characteristics of chemotherapy-induced alopecia in childhood. J Am Acad Dermatol. 2014;70:499-505. https://doi.org/10.1016/j.jaad.2013.10.034.

163. Kalpage HA, Bazylianska V, Recanati MA, Fite A, Liu J, Wan J, et al. Tissuespecific regulation of cytochrome $\mathrm{c}$ by post-translational modifications: respiration, the mitochondrial membrane potential, ROS, and apoptosis. FASEB J. 2019;33:1540-53. https://doi.org/10.1096/f.201801417R.

164. Fischer U, Janicke RU, Schulze-Osthoff K. Many cuts to ruin: a comprehensive update of caspase substrates. Cell Death Differ. 2003;10:76-100. https://doi.org/10.1038/sj.cdd.4401160.

165. Luthi AU, Martin SJ. The CASBAH: a searchable database of caspase substrates. Cell Death Differ. 2007;14:641-50. https://doi.org/10.1038/sj. cdd. 4402103 .

166. Larsen BD, Sorensen CS. The caspase-activated DNase: apoptosis and beyond. FEBS J. 2017;284:1160-70. https://doi.org/10.1111/febs.13970.

167. Van Opdenbosch N, Lamkanfi M. Caspases in cell death, inflammation, and disease. Immunity. 2019;50:1352-64. https://doi.org/10.1016/j. immuni.2019.05.020.

168. Green DR, Llambi F. Cell death signaling. Cold Spring Harb Perspect Biol. 2015. https://doi.org/10.1101/cshperspect.a006080.

169. Glushakova OY, Glushakov AO, Borlongan CV, Valadka AB, Hayes RL, Glushakov AV. Role of caspase-3-mediated apoptosis in chronic caspase-3-cleaved tau accumulation and blood-brain barrier damage in the corpus callosum after traumatic brain injury in rats. j Neurotrauma. 2018;35:157-73. https://doi.org/10.1089/neu.2017.4999.

170. Wang J, Qu J, Li Y, Feng Y, Ma J, Zhang L, et al. miR-149-5p regulates goat hair follicle stem cell proliferation and apoptosis by targeting the CMTM3/AR axis during superior-quality brush hair formation. Front Genet. 2020;11:529757. https://doi.org/10.3389/fgene.2020.529757].

171. Chen Y, Lin JS. The application of aptamer in apoptosis. Biochimie. 2017:132:1-8. https://doi.org/10.1016/j.biochi.2016.10.008.

172. Lee P, Lee DJ, Chan C, Ch'en SW, Chen I, Jamora C. Dynamic expression of epidermal caspase 8 simulates a wound healing response. Nature. 2009:458:519-23. https://doi.org/10.1038/nature07687.

173. Lee P, Gund R, Dutta A, Pincha N, Rana I, Ghosh S, et al. Stimulation of hair follicle stem cell proliferation through an IL-1 dependent activation of gammadeltaT-cells. Elife. 2017. https://doi.org/10.7554/eLife.28875.

174. Jiang N, Zhang X, Gu X, Li X, Shang L. Progress in understanding the role of IncRNA in programmed cell death. Cell Death Discov. 2021;7:30. https://doi.org/10.1038/s41420-021-00407-1.

175. Jeong D, Qomaladewi NP, Lee J, Park SH, Cho JY. The role of autophagy in skin fibroblasts, keratinocytes, melanocytes, and epidermal stem cells. J Invest Dermatol. 2020;140:1691-7. https://doi.org/10.1016/j.jid. 2019.11.023].

176. Pi W, Guo X, Su L, Xu W. BMP-2 up-regulates PTEN expression and induces apoptosis of pulmonary artery smooth muscle cells under hypoxia. PLoS ONE. 2012;7:e35283. https://doi.org/10.1371/journal. pone.0035283].

177. Chen JH, Zhang P, Chen WD, Li DD, Wu XQ, Deng R, et al. ATM-mediated PTEN phosphorylation promotes PTEN nuclear translocation and autophagy in response to DNA-damaging agents in cancer cells. Autophagy. 2015;11:239-52. https://doi.org/10.1080/15548627.2015. 1009767].

178. Huang Y, Wang S, Huang F, Zhang Q, Qin B, Liao L, et al. C-FLIP regulates pyroptosis in retinal neurons following oxygen-glucose deprivation/ recovery via a GSDMD-mediated pathway. Ann Anat. 2021;235:151672. https://doi.org/10.1016/.aanat.2020.151672.

179. Chen Y, Li Y, Guo L, Hong J, Zhao W, Hu X, et al. Bibliometric analysis of the inflammasome and pyroptosis in brain. Front Pharmacol. 2020;11:626502. https://doi.org/10.3389/fphar.2020.626502].

180. Shi J, Gao W, Shao F. Pyroptosis: gasdermin-mediated programmed necrotic cell death. Trends Biochem Sci. 2017;42:245-54. https://doi. org/10.1016/j.tibs.2016.10.004].

181. Shi J, Zhao Y, Wang K, Shi X, Wang Y, Huang H, et al. Cleavage of GSDMD by inflammatory caspases determines pyroptotic cell death. Nature. 2015;526:660-5. https://doi.org/10.1038/nature15514.

182. Hu H, Wu X, Wu G, Nan N, Zhang J, Zhu X, et al. RIP3-mediated necroptosis is regulated by inter-filament assembly of RIP homotypic interaction motif. Cell Death Differ. 2021;28:251-66. https://doi.org/10.1038/ s41418-020-0598-9.

183. Samson AL, Garnish SE, Hildebrand JM, Murphy JM. Location, location, location: a compartmentalized view of TNF-induced necroptotic signaling. Sci Signal. 2021. https://doi.org/10.1126/scisignal.abc6178.

184. Meng Y, Sandow JJ, Czabotar PE, Murphy JM. The regulation of necroptosis by post-translational modifications. Cell Death Differ. 2021;28:86183. https://doi.org/10.1038/s41418-020-00722-7.

185. Yan WT, Lu S, Yang YD, Ning WY, Cai Y, Hu XM, et al. Research trends, hot spots and prospects for necroptosis in the field of neuroscience. Neural Regen Res. 2021;16:1628-37. https://doi.org/10.4103/1673-5374. 303032.

186. Wang M, Wan H, Wang S, Liao L, Huang Y, Guo L, et al. RSK3 mediates necroptosis by regulating phosphorylation of RIP3 in rat retinal ganglion cells. J Anat. 2020;237:29-47. https://doi.org/10.1111/joa.13185.

187. Guo LM, Wang Z, Li SP, Wang M, Yan WT, Liu FX, et al. RIP3/MLKLmediated neuronal necroptosis induced by methamphetamine at 39 degrees C. Neural Regen Res. 2020;15:865-74. https://doi.org/10.4103/ 1673-5374.268902.

188. Ruan ZH, Xu ZX, Zhou XY, Zhang X, Shang L. Implications of necroptosis for cardiovascular diseases. Curr Med Sci. 2019;39:513-22. https://doi. org/10.1007/s11596-019-2067-6.

189. Lin J, Kumari S, Kim C, Van TM, Wachsmuth L, Polykratis A, et al. RIPK1 counteracts ZBP1-mediated necroptosis to inhibit inflammation. Nature. 2016;540:124-8. https://doi.org/10.1038/nature20558. 
190. Jiao H, Wachsmuth L, Kumari S, Schwarzer R, Lin J, Eren RO, et al. Z-nucleic-acid sensing triggers ZBP1-dependent necroptosis and inflammation. Nature. 2020;580:391-5. https://doi.org/10.1038/ s41586-020-2129-8.

191. Chen X, Kang R, Kroemer G, Tang D. Broadening horizons: the role of ferroptosis in cancer. Nat Rev Clin Oncol. 2021;18:280-96. https://doi. org/10.1038/s41571-020-00462-0.

192. Chen X, Kang R, Kroemer G, Tang D. Targeting ferroptosis in pancreatic cancer: a double-edged sword. Trends Cancer. 2021. https://doi.org/10. 1016/j.trecan.2021.04.005]

193. Jiang X, Stockwell BR, Conrad M. Ferroptosis: mechanisms, biology and role in disease. Nat Rev Mol Cell Biol. 2021;22:266-82. https://doi.org/10 1038/s41580-020-00324-8.

194. Gagliardi M, Cotella D, Santoro C, Cora D, Barlev NA, Piacentini M, et al. Aldo-keto reductases protect metastatic melanoma from ER stressindependent ferroptosis. Cell Death Dis. 2019;10:902. https://doi.org/10. 1038/s41419-019-2143-7.

195. Muneeb F, Hardman JA, Paus R. Hair growth control by innate immunocytes: Perifollicular macrophages revisited. Exp Dermatol. 2019;28:42531. https://doi.org/10.1111/exd.13922.

196. Liu G, Li S, Liu H, Zhu Y, Bai L, Sun H, et al. The functions of ocu-miR-205 in regulating hair follicle development in Rex rabbits. BMC Dev Biol. 2020;20:8. https://doi.org/10.1186/s12861-020-00213-5.

197. Rittmaster RS. Finasteride. N Engl J Med. 1994;330:120-5. https://doi. org/10.1056/NEJM199401133300208.

198. Leiros GJ, Attorresi Al, Balana ME. Hair follicle stem cell differentiation is inhibited through cross-talk between Wnt/beta-catenin and androgen signalling in dermal papilla cells from patients with androgenetic alopecia. Br J Dermatol. 2012;166:1035-42. https://doi.org/10.1111/j. 1365-2133.2012.10856.x].

199. Crabtree JS, Kilbourne EJ, Peano BJ, Chippari S, Kenney T, McNally $C$, et al. A mouse model of androgenetic alopecia. Endocrinology. 2010;151:2373-80. https://doi.org/10.1210/en.2009-1474.

200. Ismail FF, Meah N, de Carvalho TL, Bhoyrul B, Wall D, Sinclair R. Safety of oral bicalutamide in female pattern hair loss: a retrospective review of 316 patients. J Am Acad Dermatol. 2020;83:1478-9. https://doi.org/10 1016/j.jaad.2020.03.034

201. Sovak M, Seligson AL, Kucerova R, Bienova M, Hajduch M, Bucek M. Fluridil, a rationally designed topical agent for androgenetic alopecia: first clinical experience. Dermatol Surg. 2002;28:678-85. https://doi.org/ 10.1046/j.1524-4725.2002.02017.x.

202. Sinclair R, Patel M, Dawson TL Jr, Yazdabadi A, Yip L, Perez A, et al. Hair loss in women: medical and cosmetic approaches to increase scalp hair fullness. Br J Dermatol. 2011;165(Suppl 3):12-8. https://doi.org/10. 1111/j.1365-2133.2011.10630.x.

203. Rathnayake D, Sinclair R. Innovative use of spironolactone as an antiandrogen in the treatment of female pattern hair loss. Dermatol Clin. 2010;28:611-8. https://doi.org/10.1016/j.det.2010.03.011.

204. Zhao Y, Ren J, Hillier J, Jones M, Lu W, Jones EY. Structural characterization of melatonin as an inhibitor of the Wnt deacylase Notum. J Pineal Res. 2020;68:e12630. https://doi.org/10.1111/jpi.12630.

205. Fischer TW, Burmeister G, Schmidt HW, Elsner P. Melatonin increases anagen hair rate in women with androgenetic alopecia or diffuse alopecia: results of a pilot randomized controlled trial. Br J Dermatol. 2004;150:341-5. https://doi.org/10.1111/j.1365-2133.2004.05685.x.

206. Jung JY, Yeon JH, Choi JW, Kwon SH, Kim BJ, Youn SW, et al. Effect of dutasteride $0.5 \mathrm{mg} / \mathrm{d}$ in men with androgenetic alopecia recalcitrant to finasteride. Int J Dermatol. 2014;53:1351-7. https://doi.org/10.1111/ijd. 12060.

207. Aoi N, Inoue K, Chikanishi T, Fujiki R, Yamamoto H, Kato H, et al. 1alpha,25-dihydroxyvitamin D3 modulates the hair-inductive capacity of dermal papilla cells: therapeutic potential for hair regeneration. Stem Cells Transl Med. 2012;1:615-26. https://doi.org/10.5966/sctm. 2012-0032.

208. Bazzano GS, Terezakis N, Galen W. Topical tretinoin for hair growth promotion. J Am Acad Dermatol. 1986;15(880):90. https://doi.org/10.1016/ s0190-9622(86)80024-x]

209. Okano J, Levy C, Lichti U, Sun HW, Yuspa SH, Sakai Y, et al. Cutaneous retinoic acid levels determine hair follicle development and downgrowth. J Biol Chem. 2012;287:39304-15. https://doi.org/10.1074/jbc. M112.397273.
210. Li ZJ, Choi H-I, Choi D-K, Sohn K-C, Im M, Seo Y-J, et al. Autologous platelet-rich plasma: a potential therapeutic tool for promoting hair growth. Dermatol Surg Off Publ Am Soc Dermatol Surg. 2012;38:10406. https://doi.org/10.1111/j.1524-4725.2012.02394.x.

211. Xing F, Yi W-J, Miao F, Su M-Y, Lei T-C. Baicalin increases hair follicle development by increasing canonical Wnt/ $\beta$-catenin signaling and activating dermal papillar cells in mice. Int J Mol Med. 2018:41:2079-85. https://doi.org/10.3892/ijmm.2018.3391.

212. Kim A-R, Kim S-N, Jung I-K, Kim H-H, Park Y-H, Park W-S. The inhibitory effect of Scutellaria baicalensis extract and its active compound, baicalin, on the translocation of the androgen receptor with implications for preventing androgenetic alopecia. Planta Med. 2014;80:153-8. https:// doi.org/10.1055/s-0033-1360300.

213. Kim WS, Lee HI, Lee JW, Lim YY, Lee SJ, Kim BJ, et al. Fractional photothermolysis laser treatment of male pattern hair loss. Dermatol Surg. 2011;37:41-51. https://doi.org/10.1111/j.1524-4725.2010.01833.x.

214. Jin $H$, Zou Z, Chang H, Shen Q, Liu L, Xing D. Photobiomodulation therapy for hair regeneration: a synergetic activation of $\beta$-CATENIN in hair follicle stem cells by ROS and paracrine WNTs. Stem Cell Rep. 2021. https://doi.org/10.1016/j.stemcr.2021.04.015].

215. Fakhraei Lahiji S, Seo SH, Kim S, Dangol M, Shim J, Li CG, et al. Transcutaneous implantation of valproic acid-encapsulated dissolving microneedles induces hair regrowth. Biomaterials. 2018;167:69-79. https://doi. org/10.1016/j.biomaterials.2018.03.019.

216. Truong V-L, Bak MJ, Lee C, Jun M, Jeong W-S. Hair regenerative mechanisms of red ginseng oil and its major components in the testosteroneinduced delay of anagen entry in C57BL/6 mice. Molecules. 2017. https://doi.org/10.3390/molecules22091505.

217. Wikramanayake TC, Villasante AC, Mauro LM, Nouri K, Schachner LA Perez $\mathrm{Cl}$, et al. Low-level laser treatment accelerated hair regrowth in a rat model of chemotherapy-induced alopecia (CIA). Lasers Med Sci. 2013;28:701-6. https://doi.org/10.1007/s10103-012-1139-7.

218. Jimenez JJ, Huang HS, Yunis AA. Treatment with ImuVert/N-acetylcysteine protects rats from cyclophosphamide/cytarabine-induced alopecia. Cancer Invest. 1992;10:271-6. https://doi.org/10.3109/07357 909209032751.

219. Jimenez JJ, Yunis AA. Protection from chemotherapy-induced alopecia by 1,25-dihydroxyvitamin D3. Can Res. 1992;52:5123-5.

220. Ramot Y, Marzani B, Pinto D, Kloepper JE, Paus R. N(1)-methylspermidine, a stable spermidine analog, prolongs anagen and regulates epithelial stem cell functions in human hair follicles. Arch Dermatol Res. 2015:307:841-7. https://doi.org/10.1007/s00403-015-1592-9.

221. Ahmed NS, Ghatak S, El Masry MS, Gnyawali SC, Roy S, Amer M, et al. Epidermal $\mathrm{E}$-cadherin dependent $\beta$-catenin pathway is phytochemical inducible and accelerates anagen hair cycling. Mol Ther. 2017;25:250212. https://doi.org/10.1016/j.ymthe.2017.07.010.

222. Beoy LA, Woei WJ, Hay YK. Effects of tocotrienol supplementation on hair growth in human volunteers. Trop Life Sci Res. 2010;21:91-9.

223. Bejaoui M, Villareal MO, Isoda H. B-catenin-mediated hair growth induction effect of 3,4,5-tri-caffeoylquinic acid. Aging (Albany NY). 2019;11:4216-37. https://doi.org/10.18632/aging.102048].

224. Lee YR, Bae S, Kim JY, Lee J, Cho D-H, Kim H-S, et al. Monoterpenoid loliolide regulates hair follicle inductivity of human dermal papilla cells by activating the Akt/ß-catenin signaling pathway. J Microbiol Biotechnol. 2019:29:1830-40. https://doi.org/10.4014/jmb.1908.08018.

225. Woo H, Lee S, Kim S, Park D, Jung E. Effect of sinapic acid on hair growth promoting in human hair follicle dermal papilla cells via Akt activation. Arch Dermatol Res. 2017;309:381-8. https://doi.org/10.1007/ s00403-017-1732-5.

226. Kim YE, Choi HC, Nam G, Choi BY. Costunolide promotes the proliferation of human hair follicle dermal papilla cells and induces hair growth in C57BL/6 mice. J Cosmetic Dermatol. 2019;18:414-21. https://doi.org/ 10.1111/jocd.12674.

227. Cheon HI, Bae S, Ahn KJ. Flavonoid silibinin increases hair-inductive property via Akt and Wnt/ $\beta$-catenin signaling activation in 3-dimensional-spheroid cultured human dermal papilla cells. J Microbiol Biotechnol. 2019;29:321-9. https://doi.org/10.4014/jmb.1810.10050.

228. Zhang H, Shi Q, Nan W, Wang Y, Wang S, Yang F, et al. Ginkgolide B and bilobalide promote the growth and increase $\beta$-catenin expression in hair follicle dermal papilla cells of American minks. BioFactors. 2019;45:950-8. https://doi.org/10.1002/biof.1562. 
229. Zhou L, Wang H, Jing J, Yu L, Wu X, Lu Z. Morroniside regulates hair growth and cycle transition via activation of the Wnt/ $\beta$-catenin signaling pathway. Sci Rep. 2018;8:13785. https://doi.org/10.1038/ s41598-018-32138-2.

230. Park H-J, Zhang N, Park DK. Topical application of Polygonum multiflorum extract induces hair growth of resting hair follicles through upregulating Shh and $\beta$-catenin expression in C57BL/6 mice. J Ethnopharmacol. 2011;135:369-75. https://doi.org/10.1016/j.jep.2011.03.028.

231. Zhou Y, Tang G, Li X, Sun W, Liang Y, Gan D, et al. Study on the chemical constituents of nut oil from Prunus mira Koehne and the mechanism of promoting hair growth. J Ethnopharmacol. 2020;258:112831. https:// doi.org/10.1016/j.jep.2020.112831.

232. Zhang N-N, Park DK, Park H-J. Hair growth-promoting activity of hot water extract of Thuja orientalis. BMC Complement Altern Med. 2013;13:9. https://doi.org/10.1186/1472-6882-13-9.

233. Shim JH. Hair growth-promoting effect of human dermal stem/ progenitor cell-derived conditioned medium. Tissue Eng Regen Med. 2015;12:268-75. https://doi.org/10.1007/s13770-015-0012-8.

234. Liu J, Xu Y, Wu Q, Ding Q, Fan W. Sirtuin-1 protects hair follicle stem cells from TNFa-mediated inflammatory stress via activating the MAPK-ERKMfn2 pathway. Life Sci. 2018;212:213-24. https://doi.org/10.1016/j.lfs. 2018.10.003.

235. Amberg N, Holcmann M, Stulnig G, Sibilia M. Effects of Imiquimod on hair follicle stem cells and hair cycle progression. J Invest Dermatol. 2016;136:2140-9. https://doi.org/10.1016/j.jid.2016.06.613.

236. Lough D, Dai H, Yang M, Reichensperger J, Cox L, Harrison C, et al. Stimulation of the follicular bulge LGR5 + and LGR6 + stem cells with the gut-derived human alpha defensin 5 results in decreased bacterial presence, enhanced wound healing, and hair growth from tissues devoid of adnexal structures. Plast Reconstr Surg. 2013;132:1159-71. https://doi.org/10.1097/PRS.0b013e3182a48af6.

237. Biehs B, Dijkgraaf GJP, Piskol R, Alicke B, Boumahdi S, Peale F, et al. A cell identity switch allows residual BCC to survive Hedgehog pathway inhibition. Nature. 2018;562:429-33. https://doi.org/10.1038/ s41586-018-0596-y.

238. Gentile P, Scioli MG, Cervelli V, Orlandi A, Garcovich S. Autologous micrografts from scalp tissue: trichoscopic and long-term clinical evaluation in male and female androgenetic alopecia. Biomed Res Int. 2020;2020:7397162. https://doi.org/10.1155/2020/7397162.

239. Gentile P. Autologous cellular method using micrografts of human adipose tissue derived follicle stem cells in androgenic alopecia. Int J Mol Sci. 2019. https://doi.org/10.3390/ijms20143446.

240. Gentile P, Scioli MG, Bielli A, Orlandi A, Cervelli V. Stem cells from human hair follicles: first mechanical isolation for immediate autologous clinical use in androgenetic alopecia and hair loss. Stem Cell Investig. 2017;4:58. https://doi.org/10.21037/sci.2017.06.04.

241. Gentile P, Garcovich S, Bielli A, Scioli MG, Orlandi A, Cervelli V. The effect of platelet-rich plasma in hair regrowth: a randomized placebo-controlled trial. Stem Cells Transl Med. 2015;4:1317-23. https://doi.org/10. 5966/sctm.2015-0107.

242. Gentile P, Cole JP, Cole MA, Garcovich S, Bielli A, Scioli MG, et al. Evaluation of not-activated and activated PRP in hair loss treatment: role of growth factor and cytokine concentrations obtained by different collection systems. Int J Mol Sci. 2017. https://doi.org/10.3390/ijms 180204 08.

243. Khatu SS, More YE, Gokhale NR, Chavhan DC, Bendsure N. Platelet-rich plasma in androgenic alopecia: myth or an effective tool. J Cutan Aesthet Surg. 2014;7:107-10. https://doi.org/10.4103/0974-2077.138352.

244. Gentile P, Garcovich S, Scioli MG, Bielli A, Orlandi A, Cervelli V. Mechanical and controlled PRP injections in patients affected by androgenetic alopecia. J Vis Exp. 2018. https://doi.org/10.3791/56406.

245. Cervelli V, Garcovich S, Bielli A, Cervelli G, Curcio BC, Scioli MG, et al. The effect of autologous activated platelet rich plasma (AA-PRP) injection on pattern hair loss: clinical and histomorphometric evaluation. Biomed Res Int. 2014;2014:760709. https://doi.org/10.1155/2014/760709.

246. Gentile P, Garcovich S. Autologous activated platelet-rich plasma (AAPRP) and non-activated (A-PRP) in hair growth: a retrospective, blinded, randomized evaluation in androgenetic alopecia. Expert Opin Biol Ther. 2020;20:327-37. https://doi.org/10.1080/14712598.2020.1724951.
247. Adil A, Godwin M. The effectiveness of treatments for androgenetic alopecia: a systematic review and meta-analysis. J Am Acad Dermatol. 2017;77:136-41 e5. https://doi.org/10.1016/j.jaad.2017.02.054.

248. Gentile P, Garcovich S. Systematic review of platelet-rich plasma use in androgenetic alopecia compared with minoxidil((R)), finasteride((R)), and adult stem cell-based therapy. Int J Mol Sci. 2020. https://doi.org/ 10.3390/ijms21082702.

249. Gentile P, Scioli MG, Bielli A, De Angelis B, De Sio C, De Fazio D, et al. Platelet-rich plasma and micrografts enriched with autologous human follicle mesenchymal stem cells improve hair re-growth in androgenetic alopecia. Biomolecular pathway analysis and clinical evaluation. Biomedicines. 2019. https://doi.org/10.3390/biomedicines7020027].

250. Ito M, Yang Z, Andl T, Cui C, Kim N, Millar SE, et al. Wnt-dependent de novo hair follicle regeneration in adult mouse skin after wounding. Nature. 2007:447:316-20. https://doi.org/10.1038/nature05766.

251. Dong L, Hao H, Xia L, Liu J, Ti D, Tong C, et al. Treatment of MSCs with Wnt1a-conditioned medium activates DP cells and promotes hair follicle regrowth. Sci Rep. 2014:4:5432. https://doi.org/10.1038/srep05432.

252. Leavitt $E$, Lask G, Martin S. Sonic hedgehog pathway inhibition in the treatment of advanced basal cell carcinoma. Curr Treat Options Oncol. 2019;20:84. https://doi.org/10.1007/s11864-019-0683-9.

253. Iglesias-Bartolome R, Torres D, Marone R, Feng X, Martin D, Simaan $M$, et al. Inactivation of a Galpha(s)-PKA tumour suppressor pathway in skin stem cells initiates basal-cell carcinogenesis. Nat Cell Biol. 2015;17:793-803. https://doi.org/10.1038/ncb3164.

254. Seldin L, Macara IG. DNA damage promotes epithelial hyperplasia and fate mis-specification via fibroblast inflammasome activation. Dev Cell. 2020;55:558-736. https://doi.org/10.1016/j.devcel.2020.09.021.

255. Sabat R, Wolk K, Loyal L, Docke WD, Ghoreschi K. T cell pathology in skin inflammation. Semin Immunopathol. 2019;41:359-77. https://doi.org/ 10.1007/s00281-019-00742-7.

256. Liu J, Xu Y, Wu Q, Ding Q, Fan W. Sirtuin 1 protects hair follicle stem cells from TNFalpha-mediated inflammatory stress via activating the MAPKERK-Mfn2 pathway. Life Sci. 2018;212:213-24. https://doi.org/10.1016/j. Ifs.2018.10.003.

257. Yang R, Yang S, Zhao J, Hu X, Chen X, Wang J, et al. Progress in studies of epidermal stem cells and their application in skin tissue engineering. Stem Cell Res Ther. 2020;11:303. https://doi.org/10.1186/ s13287-020-01796-3.

258. Yang R, Liu F, Wang J, Chen X, Xie J, Xiong K. Epidermal stem cells in wound healing and their clinical applications. Stem Cell Res Ther. 2019;10:229. https://doi.org/10.1186/s13287-019-1312-z.

259. Gentile P, Calabrese C, De Angelis B, Dionisi L, Pizzicannella J, Kothari A, et al. Impact of the different preparation methods to obtain autologous non-activated platelet-rich plasma (A-PRP) and activated platelet-rich plasma (aa-prp) in plastic surgery: wound healing and hair regrowth evaluation. Int J Mol Sci. 2020. https://doi.org/10.3390/ijms21020431.

260. Gentile P, Alves R, Cole JP, Andjelkov K, Van Helmelryck T, Fernandez $J$, et al. AIRMESS - Academy of International Regenerative Medicine \& Surgery Societies: recommendations in the use of platelet-rich plasma (PRP), autologous stem cell-based therapy (ASC-BT) in androgenetic alopecia and wound healing. Expert Opin Biol Ther 2021: 1-7. https:// doi.org/10.1080/14712598.2021.1908995

261. Wang X, Wang X, Liu J, Cai T, Guo L, Wang S, et al. Hair follicle and sebaceous gland de novo regeneration with cultured epidermal stem cells and skin-derived precursors. Stem Cells Transl Med. 2016;5:1695-706. https://doi.org/10.5966/sctm.2015-0397.

262. Wang X, Chen H, Tian R, Zhang Y, Drutskaya MS, Wang C, et al. Macrophages induce AKT/beta-catenin-dependent Lgr5(+) stem cell activation and hair follicle regeneration through TNF. Nat Commun. 2017;8:14091. https://doi.org/10.1038/ncomms14091.

263. van Es JH, Sato T, van de Wetering M, Lyubimova A, Yee Nee AN, Gregorieff $A$, et al. DII1 + secretory progenitor cells revert to stem cells upon crypt damage. Nat Cell Biol. 2012;14:1099-104. https://doi.org/10.1038/ ncb2581.

\section{Publisher's Note}

Springer Nature remains neutral with regard to jurisdictional claims in published maps and institutional affiliations. 